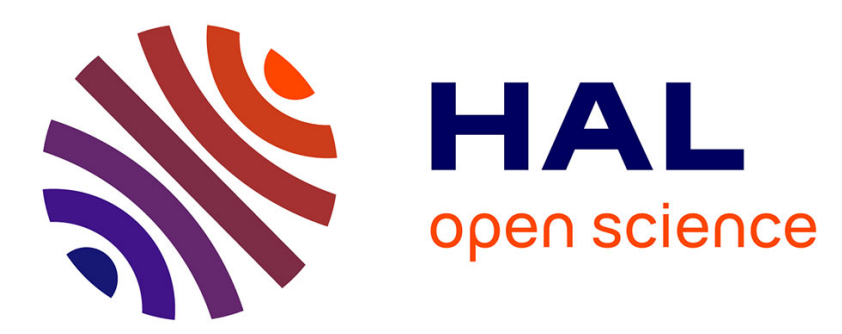

\title{
Multifractal characterisation of a simulated surface flow: A case study with Multi-Hydro in Jouy-en-Josas, France
} Auguste Gires, Jean-Baptiste Abbes, Igor da Silva Rocha Paz, Ioulia Tchiguirinskaia, D Schertzer

\section{- To cite this version:}

Auguste Gires, Jean-Baptiste Abbes, Igor da Silva Rocha Paz, Ioulia Tchiguirinskaia, D Schertzer. Multifractal characterisation of a simulated surface flow: A case study with Multi-Hydro in Jouyen-Josas, France. Journal of Hydrology, 2018, 558, pp.482 - 495. 10.1016/j.jhydrol.2018.01.062 . hal-01704091

\section{HAL Id: hal-01704091 \\ https://hal-enpc.archives-ouvertes.fr/hal-01704091}

Submitted on 8 Feb 2018

HAL is a multi-disciplinary open access archive for the deposit and dissemination of scientific research documents, whether they are published or not. The documents may come from teaching and research institutions in France or abroad, or from public or private research centers.
L'archive ouverte pluridisciplinaire HAL, est destinée au dépôt et à la diffusion de documents scientifiques de niveau recherche, publiés ou non, émanant des établissements d'enseignement et de recherche français ou étrangers, des laboratoires publics ou privés. 
1 Multifractal characterisation of a simulated surface flow: a case study with

2 Multi-Hydro in Jouy-en-Josas, France

3 Auguste Gires ${ }^{* 1}$, Jean-Baptiste Abbes ${ }^{1}$, Igor da Silva Rocha Paz ${ }^{1,2}$, Ioulia Tchiguirinskaia ${ }^{1}$,

4 Daniel Schertzer $^{1}$

5 1. HMCO, École des Ponts ParisTech, U. Paris-Est, Champs-sur-Marne, France,

6 2. Instituto Militar de Engenharia, Rio de Janeiro, Brazil

$7 *$ Corresponding author: Auguste Gires, auguste.gires@enpc.fr (phone +33 1641536 48; fax

$8+33164153764)$

9

Abstract

In this paper we suggest to innovatively use scaling laws and more specifically

Universal Multifractals (UM) to analyse simulated surface runoff and compare the retrieved

13 scaling features with the rainfall ones. The methodology is tested on a $3 \mathrm{~km}^{2}$ semi-urbanised

14 with a steep slope study area located in the Paris area along the Bièvre River. First Multi-

Hydro, a fully distributed model is validated on this catchment for four rainfall events

measured with the help of a C-band radar. The uncertainty associated with small scale

unmeasured rainfall, i.e. occurring below the $1 \mathrm{~km} \times 1 \mathrm{~km} \times 5$ min observation scale, is quantified with the help of stochastic downscaled rainfall fields. It is rather significant for

19 simulated flow and more limited on overland water depth for these rainfall events. Overland depth is found to exhibit a scaling behaviour over small scales (10 m - $80 \mathrm{~m}$ ) which can be related to fractal features of the sewer network. No direct and obvious dependency between the overland depth multifractal features (quality of the scaling and UM parameters) and the rainfall ones was found. 
1) Introduction

The combined effects of a growing urbanisation - approximately $80 \%$ of Europe's population will live in cities by 2020 (EEA, 2014) - and potential increase of extreme events as a consequence of climate change (IPCC, 2013) expose more and more people to surface pluvial flooding. Pitt (2008) carried out a review on flood events in the United Kingdom and showed that two thirds of the flood related damages were caused by surface water flooding.

Urban flooding has become a growing concern in Europe, hence a significant number of

European research projects address this issue, along with national counterparts. The purpose of these projects is to increase the resilience of urban areas through improvement of both real time management of extreme events and long term planning. We can cite FP7 SMARTesT (http://floodresilience.eu/), CORFU (http://www.corfu-fp7.eu/), Climate KIC Blue Green Dream (www.bgd.org.uk) or the INTERREG IV RainGain project (http://www.raingain.eu) among others.

There is a need to improve the understanding of urban surface flow. Indeed, there is a growing interest for 2D models in urban environment for both operational and research applications (Bolle et al., 2006; Carr and Smith, 2006; Chen et al., 2007; Deltares, 2013; DHI, 2011; Giangola-Murzyn et al., 2014; Innovyze, 2012, 2103; Phillips et al., 2005; XP Solutions, 2012). Such models aim at actually modelling processes in a physically based manner, while the most commonly used semi-distributed models take them into account through tailored lumped models. In case of overflow they simply consider a volume output from the sewer system and deduce a local water depth, but the dynamical behaviour of the water added on the ground is not addressed. Basically, urban surface flow is not commonly 
capable of grasping its intrinsic complexity visible across all scales. Indeed, it results from the non-linear interactions between the highly spatially and temporally variable rainfall field, the topography and the strongly inhomogeneous land use cover.

In this paper we suggest to use multifractal tools, which are commonly used in geophysics to characterise and simulate fields extremely variable over a wide range of scales; such as wind turbulence, rainfall, river flow or topography (see Schertzer and Lovejoy, 2011 for review). Such tools have seldom been used in an urban context. Gires et al. (2013, 2014b) used them to downscale rainfall to quantify the uncertainty associated with small scale rainfall variability, or to characterise the variability across scales of simulated flow in conduits (sewer). To the knowledge of the authors it has never been used to study either surface runoff flow (urban drainage) or surface flow in general including stream rivers. Investigating the potential multifractal features of surface flow and notably whether it inherits rainfall features is the main purpose of this paper and constitute its main novelty. In addition, this case study will also be used to quantify the uncertainty associated with small scale rainfall variability, not only on the simulated flow which has already been done on other catchments, but also on the surface flow.

Given the lack of measurements of distributed data of surface runoff, outputs of a numerical model are analysed. The model used is Multi-Hydro (El Tabach et al., 2009 for an initial version and Giangola-Murzyn, 2014 for a recent one) developed at the Ecole des Ponts ParisTech. It is implemented on a $3.017 \mathrm{~km}^{2}$ peri-urban catchment in Jouy-en-Josas (SouthEast of Paris), which exhibits steep slopes and both forest and urbanised areas. Achieving such an analysis is relevant only if a distributed rainfall field is used as model input. MétéoFrance radar mosaics with a resolution of $1 \mathrm{~km}$ in space and 5 min time (Tabary, 2007; Tabary et al., 2007) for four events that occurred between 2009 and 2011 are used. When 
needed, the rainfall field is downscaled both in space and time from the raw radar data, in order to simulate the improvement that could be made with higher radar resolution. The model and the study area data for its implementation are presented in details in section 2. The multifractal framework and analysis methods are presented in section 3 . Results are discussed in section 4 and 5. More precisely, the validation of the model and quantification of the uncertainty associated with small scale unmeasured rainfall variability on both simulated sewer flow and maximum water depth is carried out in section 4. Multifractal characterization of overland water depth is addressed in section 5. Main conclusions are highlighted in section 6.

2) Model and catchment 85

\section{1) The Multi-Hydro model}

Multi-Hydro is a multi-module model whose goal is to model and predict the impacts of rainfall events in urban and peri-urban areas. In this paper, there is an emphasis on heavy rainfall events. Following the approach of various recent developments of hydrological models (Djordjevic et al., 1999; Fletcher et al., 2013; Hsu et al., 2000; Jankowfsky, 2011;

Rodriguez et al., 2008); it makes different modules interact, each of them echoing a portion of the water cycle in urban areas (surface runoff, infiltration, ground water flow, sewer flow).

$$
\text { Each of the modules integrated in Multi-Hydro relies on open-source software }
$$
packages that have already been widely used and validated by the scientific community. The surface module is based on TREX (Two dimensional Runoff, Erosion and eXport model, Velleux et al., 2011) which solves fluid mechanics equations for surface flow (diffusive wave 
approximation of 2D Saint-Venant, see p. 6-7 of the TREX user manual) and infiltration (simplification of Green and Ampt equation). The sewer or drainage module, which is based on SWMM developed by the US Environmental Agency (Storm Water Management Model, Rossman, 2010), is a 1D-model dealing with sewer flows through numerical solutions of Saint-Venant $1 \mathrm{D}$ equations in pipes. The interactions between the surface and sewer flow is handled through the gully pixels. These interactions (input or output of water) between the surface and sewer flow are carried out every $3 \mathrm{~min}$. When there is no overflow, gully pixels are considered to have an infinite infiltration rate, and the water passing through them is directly inputted into the corresponding node of the sewer model. This way of modelling implies that a large transport capacity is assumed for gully, especially with $10 \mathrm{~m}$ pixel size as in this paper (see below). Future developments of Multi-Hydro will enable to improve the model with regards to this coarse assumption. They could notably rely on the experimental and computational studies of gully inflow capacity, including 3D CFD studies, which analyse phases in the flow, inlet capacity, reverse flow when the piezometric level in the sewer is beyond the ground level (Despotovic et al., 2005; Djorjevic et al., 2005). In case of sewer overflow through a node, the corresponding gully pixel is converted into a road pixel and the water exiting the node is inputted on this pixel (considered as a source in TREX). There is also a module handling ground water flow which was not included in this study to limit computation time.

In order to run Multi-Hydro, data needs to be shaped in a standard format. Commonly available Geographical Information System (GIS) data, such as land use and topography provided in France by IGN (the French agency producing geographical information) are inputted to MH-AssimTool (Richard et al., 2014). This software formats the inputs with the desired resolution and makes Multi-Hydro a transportable model, rather easy to implement on a new catchment. Once a resolution is chosen, one has to affect an elevation and a land use 
123 class to each pixel. The elevation is obtained by an interpolation of the raw available data.

124 With regards to the land use, a priority order has been determined to assign a unique land use 125 class for a given pixel according to the hydrological importance of the given class instead of

126 the surface represented by this class: if a gully is located on a pixel, the entire pixel will be

127 considered as a gully. This process is repeated in the following order for this case study:

128 roads, houses, forest, grass, and water surface. See Ichiba et al. (2017) for a comparison with 129 other possible strategies.

130 In this paper, the model was implemented with pixels of size $10 \mathrm{~m} \times 10 \mathrm{~m}$. Given the

131 obtained results discussed below it was not found necessary to run it at higher resolution

132 which makes computation time too long. For an in-depth analysis of the relation between the

133 selected pixel size and simulated flow, which is not the purpose of this paper, refer to Ichiba

134 (2016). Multi-hydro was not calibrated, i.e. standard values for the parameters describing a

135 land use class are used (hydraulic conductivity, capillary suction, moisture deficit, Manning's

136 coefficient, depth of interception). Raw or downscaled radar data are used as input of the

137 model.

139 2.2) Presentation of the study area

142 South-west of Paris). It occupies a $3.017 \mathrm{~km}^{2}$ area, mainly on the left bank of the Bièvre

143 River. A small portion of the right bank near the river bed is also included. The remaining

144 portion of the right bank is drained to a small river that flows into the Bièvre River

145 downstream the outlet of the studied catchment. The Bièvre River is a tributary of the Seine

146 River which it meets in Paris. It flows through increasingly urbanised areas along its $33 \mathrm{~km}$

147 path. This has led to strongly modify its natural bed, both in underground pipes which are 
148 integrated in the storm water sewer system, or in a highly artificial open air bed. An effort is

149 currently undertaken to restore its "natural" aspect.

150 A striking feature of this catchment is that, unlike the previous ones studied with

151 Multi-Hydro (Giangola-Murzyn et al., 2014; Gires et al., 2014a), it exhibits steep slopes.

152 There is a difference of approximately $100 \mathrm{~m}$ between the plateau in the north of the

153 catchment, and the outlet of the catchment (Fig. 1). The downhill portion strengthens overland

154 runoff, and the combination of pluvial and fluvial processes on the river bank has led to

155 severe flooding in 1973 and 1982. Some details are available on the SIAVB (Syndicat

156 Intercommunal d'Assainissement de la Vallée de la Bièvre, the local authority in charge of

157 urban drainage of the area) website http://www.siavb.fr/gestion_des_crues.aspx. Urbanisation

158 and imperviousness are concentrated along the river bank, and on a housing estate along one

159 major North-South road. The remaining of this semi-urban catchment is mainly made of

160 forests. The sewer system is a separate one, and the storm water is routed into the Bièvre

161 River.

162 Following the severe flooding, the SIAVB has created 15 storage basins (integrated in

163 the landscape) along the Bièvre River to mitigate flooding risks. One, the Bassin des Bas Près,

164 is located just upstream the Jouy-en-Josas catchment. The outlet of this basin is equipped with

165 flow and height gauges operated in real time. There is a second measuring point of water

166 depth, few meters upstream the outlet of the catchment, at the "Pont de Pierre" (Fig. 1). This

167 gauge has been installed to monitor the river level and to protect a music school by triggering

168 a warning system in case of elevated height. Given the position of the two measuring points,

169 Multi-hydro will only be validated on the area drained by the sewer network represented in

170 green in Fig. 1. The forest corresponds approximately to $60 \%$ of the catchment $\left(\sim 2 \mathrm{~km}^{2}\right)$.

171 Although it is only possible to validate the implementation of the model on a portion of the

172 catchment, the whole area is modelled to ensure the accuracy of flow over the areas actually 
used for validation. The river is part of the storm water sewer system in Jouy-en-Josas and is modelled as a pipe in Multi-Hydro drainage module. Indeed, through the city, the river bed is highly artificial or even underground. The long and West - East oriented pipe located in the South of the Basin (Fig. 1, left) is actually the Bièvre River.

2.3) Fractal dimensions of the impervious surfaces and of the sewer system

The studied catchment is located in a semi-urbanised area. The impervious surfaces are highly relevant for hydrology since they basically correspond to areas where runoff is quickly active during a storm event. Thanks to the determination of land use per pixel in $\mathrm{MH}-$ AssimTool, the evaluation of the impervious areas can be done in an apparent simple way by calculating the number of pixels of roads, buildings and gullies (since the water falling on gully pixels is immediately routed to the sewer network, they are considered as impervious).

This impervious surface depends on the resolution at which it is computed. Indeed, an imperviousness of $55 \%, 50 \%, 42 \%, 32 \%$ and $25 \%$ is obtained with pixels of size $20,15,10$, $5,2 \mathrm{~m}$ respectively. This is due to the priority order set in the data assimilation tool that affects a land use for each pixel. This order prioritizes impervious areas (Fig. 2). Obviously these values strongly depend on the approach implemented to affect a land use class to a pixel. As previously mentioned, comparison with other approaches can be found in Ichiba et al. (2017). Investigations on the possibility of having different pixel size according to the land use should also be envisaged in the future, in order to for instance refine the pixels for roads and gullies and coarser them for forests. Coming back to the imperviousness percentages found in this paper, it is possible to use the notion of fractal dimension, which is scale invariant, to explain these figures. The fractal dimension $D_{\mathrm{F}}$ of a geometrical set (here the impervious pixels) is obtained with the help of the following equation: 
where $N_{\lambda}$ is the number of impervious pixels, and $\lambda$ is the resolution defined as the ratio

200 between the outer scale $L$ of the phenomenon and the observation scale $l\left(\lambda=\frac{L}{l}\right)$. It

201 characterizes the space occupied by a geometrical set in a scale invariant way. The symbol $\approx$ 202 denotes an asymptotic convergence and absorbs slowly varying prefactors.

204 dimension. Indeed Eq. 1 is plotted in $\log -\log$ for the geometrical set consisting of the 205 impervious pixels at the $2-\mathrm{m}$ resolution (imperviousness of $25 \%$ ), and a straight line is 206 retrieved on the whole range of scales, i.e. $2 \mathrm{~m}-2048 \mathrm{~m}$ (Fig. 3.a). This a basic feature of the 207 catchment. The fact that the points corresponding to the catchment representation at 20,15 , 208 10, 5, 2 m obtained with MH-AssimTool are along this straight line (circled cross on Fig. 3.a) is simply a consequence of the priority order set for affecting a land use class to a pixel (impervious classes are prioritised over pervious ones). This confirms the fact that even though the represented imperviousness varies with scale, a feature (the fractal dimension) is conserved and provides a quantification of the level of urbanisation. We find $D_{\mathrm{F}}$ equal to 1.73 for this catchment. In a previous study Gires et al. (2014a), found that for a highly urbanised area in Seine-Saint-Denis (North-East of Paris), the fractal dimension was of 1.85 from on scales ranging from $1 \mathrm{~m}$ to $1024 \mathrm{~m}$. Given that this catchment is less urbanised, it was 216 expected to obtain a smaller fractal dimension. 
network becomes apparent, and exhibits a scaling behaviour. For large scales the value is slightly smaller than the 1.85 found on the Seine-Saint-Denis catchment in Gires et al. (2014a) which is consistent with the fact that this one is less urbanised. The similarity between both fractal dimensions (imperviousness and large scale sewers) indicates that it is a relevant way of quantifying a level of urbanisation for the area. See Gires et al. (2017) for an extension of this approach to 10 areas in 5 European countries.

\section{4) Rainfall data}

Four rainfall events, which occurred between 2009 and 2011, are studied in this paper. Simulations are performed using Météo-France radar mosaic, which provides a spatially distributed data with a resolution of $1 \mathrm{~km} \times 1 \mathrm{~km} \times 5$ min (the closest radar is the C-band one of Trappes located $15 \mathrm{~km}$ West). For three events the data recorded with the help of a rain gauge operated by the SIAVB located a few hundred meters south of the catchment at the "Bassin des Bas Près" is also available. Because of (i) the standard $0.2 \mathrm{~mm}$ discretization issue of the tipping bucket rain gauge (data is number of tips equal to $0.2 \mathrm{~mm}$ ) which prevents it from providing reliable intensity, (ii) the gap between the observation scales of the two measuring devices (see Gires et al., 2014b, for an in-depth analysis of this issue) and (iii) the fact that the rain gauge is furthermore outside of the catchment; it is not possible to use the rain gauge data for other purpose than a rough check of the accuracy of radar data. It is done by comparing the cumulative volumes of rainfall for each studied event which are displayed in Table 1 along with their main features. Gires et al. (2014b) used data from dense network of point measurement devices (rain gauges or disdrometers) distributed over $1 \mathrm{~km}^{2}$ and showed that the cumulative depth differences between devices could reach more than $40 \%$ for individual rainfall events (of the same order of magnitude as the one discussed here). They 
showed with the help of numerical simulations that similar values were found simply taking

249 into account small scale rainfall variability. Here the maximum observed differences are $34 \%$,

250 which suggests that the agreement between the two devices is acceptable, i.e. smaller than 251 expected uncertainty simply due to the scale gap between the two measuring devices. Authors 252 did not have access to longer time series of both radar and rain gauge to perform a more in253 depth evaluation of the radar versus rain gauge measurement for this specific point, which 254 would be the topic of another study. The temporal evolutions of the radar rain rate averaged 255 over the catchment are displayed in Fig. 4. These events were selected because they are heavy 256 ones. However they are not extreme ones, indeed over durations of $1 \mathrm{~h}$ and $4 \mathrm{~h}$, only the 14 257 July 2010 event has a return period greater than 1 year (data from a rain gauge located in the 258 Paris area that was available to the authors was used to obtain these estimates). For the July 259 event, the return period is of about 1 year for a duration of $1 \mathrm{~h}$ and of about 2 years for a 260 duration of $4 \mathrm{~h}$.

3) Methods

\section{1) Multifractal framework}

The Multifractal framework is used for several purposes throughout this paper to 265 characterize the variability across scales of fields, and is therefore presented here in a generic 266 way. Only basic properties are discussed here, and interested readers are referred to the recent 267 review by Schertzer and Lovejoy (2011) for more details. The general assumption of 268 multifractal fields is that they are generated by an underlying scale invariant multiplicative 269 cascade process. In such process, a structure at a given scale is divided into smaller structures 270 at smaller scale and the value of a child structure is equal to the value of the parent structure 271 multiplied of a random increment. The process is scale invariant in the sense that the way 272 structures are divided into sub-structures and the probability distribution of the random 
273

274

275

multiplicative increments are the same at all scales. A consequence is that statistical properties of such fields are conserved across scales. More precisely let us denote $\varepsilon_{\lambda}$ a field at resolution $\lambda(=L / l$, where $l$ is the observation scale and $L$ the outer scale of the phenomenon as for the fractal dimension definition). The probability of exceeding a given threshold $\left(\lambda^{\gamma}\right)$, defined with the help of the scale invariant notion of singularity $\gamma$ (the thresholds depend on the observation scale, but not the singularity),

$$
\operatorname{Pr}\left(\varepsilon_{\lambda} \geq \lambda^{\gamma}\right) \approx \lambda^{-c(\gamma)} \quad \text { Eq. } 2 \text {, }
$$

and the moment of order $q$,

$$
\left\langle\varepsilon_{\lambda}^{q}\right\rangle \approx \lambda^{K(q)} \quad \text { Eq. } 3
$$

exhibit a power law relation with regards to the resolution at which they are computed. As for Eq. 1 , the symbol $\approx$ denotes an asymptotic convergence and absorbs slowly varying prefactors. Equations 2 and 3 define respectively the codimension function $c(\gamma)$ and the moment scaling function $K(q)$, which both fully characterize the variability across scales of the field. $c(\gamma)$ and $K(q)$ contain the same information and are related by a Legendre transform (Parisi and Frish, 1985). Eq. 2 can be understood from the simpler notion of fractal dimension (Eq. 1). Indeed, an intuitive interpretation of a multifractal field is that the geometrical sets made of each portion of the field greater than given thresholds are fractal and characterized by fractal dimensions. To be mathematically more rigorous the notion of threshold is replaced by the scale invariant one of singularity.

By generalizing the central limit theorem Schertzer and Lovejoy (1987) showed that any conservative scale-invariant multiplicative processes converge toward Universal Multifractals (in a similar way as re-normalized sum of identical and independent random variables converge toward normal distribution as long as their variance is defined). For Universal Multifractals (UM), i.e. this limit behaviour, $K(q)$ and $\mathrm{c}(\gamma)$ functions are defined 
with the help of only two relevant parameters with a physical interpretation. They are known as UM parameters $C_{1}$ and $\alpha$ :

$299-C_{1}$ is the mean intermittency which measures the average sparseness of the field. $C_{1}=0$ for a

300 homogeneous field.

$301-\alpha$ is the multifractality index $(0 \leq \alpha \leq 2)$ and measures how fast the intermittency evolves when considering level of activity slightly different from the average one.

extremes of a field is the scale invariant notion of maximum probable singularity $\gamma_{\mathrm{s}}$ observable (Hubert et al., 1993; Douglas and Barros, 2003; Royer et al., 2008; Gires et al., 2014a). It is defined for a unique sample by

$c\left(\gamma_{s}\right)=d$

Eq. 4

Where $d$ is the dimension of the embedding space, i.e. $d=1$ for time series and $d=2$ for 309 maps.

The power spectrum (Fourrier transform of the auto-correlation function) of such

311 multifractal field exhibits a scaling relation with wave number $k$ :

$$
E(k) \approx k^{-\beta} \quad \text { Eq. } 5
$$

313 where $\beta$ is the spectral slope.

The purpose of this section is to explain the approach implemented to quantify the uncertainty associated with small scales rainfall variability, i.e. which is occurring below the 1 $\mathrm{km} \times 5$ min scale currently provided by the C-band radar operating in this area. The same methodology as in Gires et al. (2013, 2014a) is implemented, and only basic ideas are explained here. Firstly, an ensemble of downscaled rainfall fields is generated, then each realisation is inputted into the numerical model and finally the disparities within the ensemble 
of outputs, which reflect the studied uncertainty, are analysed and quantified. 100 sample

323

ensembles are used. The downscaling technique relies on the Universal Multifractal

framework. It basically consists in stochastically continuing a space-time cascade process that has been validated on the available range of scales. The resolution of the downscaled rainfall field is $12 \mathrm{~m}$ in space and $20 \mathrm{~s}$ in time starting from the original $1 \mathrm{~km}$ and $5 \mathrm{~min}$ of the available radar data. The process has been validated down to such small scales (Gires et al., 2014b).

The disparities among the simulated ensembles are quantified with the help of quantile analysis. Let us first illustrate this with the flow output, but the same is done for maximum water depth at each pixel. For each time step the 5, 25, 75 and $95 \%$ quantiles are computed, and give the envelop curves $\mathrm{Q}_{0.05}, \mathrm{Q}_{0.25}, \mathrm{Q}_{0.75}$, and $\mathrm{Q}_{0.95}$, respectively. The width between these curves characterizes the uncertainty interval on simulated flow. It is quantified with the help of two pseudo-coefficients of variation computed as:

$C V_{95}{ }^{\prime}=\frac{Q_{0.95}\left(t_{P F, \text { radar }}\right)-Q_{0.05}\left(t_{P F, \text { radar }}\right)}{2 * P F_{\text {radar }}} \quad$ Eq 6.a

$C V_{75}^{\prime}=\frac{Q_{0.75}\left(t_{P F, \text { radar }}\right)-Q_{0.25}\left(t_{P F, \text { radar }}\right)}{2 * P F_{\text {radar }}} \quad$ Eq 6.b where $t_{P F, \text { radar }}$ is the time of the peak flow simulated with the raw radar data $\left(P F_{\text {radar }}\right) .$.

\section{3) Multifractal analysis of overland water depth maps}

There is no distributed data available for overland water depth over large areas, but it is possible to study the fields obtained with the help of numerical simulations with spatially distributed rainfall as input. Maps of water depth during runoff at the end of each 3 min Multi-Hydro loop are studied. 
346 from the map of the catchment to carry out the analysis. Both ensemble analysis (i.e.

347 considering all successive maps as independent realisations of the same process and upscaling 348 them individually before taking the mean in Eq. 2 and 3) and individual time step analysis

349 (i.e. to obtain temporal evolutions of the various parameters) are performed. Finally, analyses 350 are done in $2 \mathrm{D}$ on the maps but also in $1 \mathrm{D}$ on the columns or the lines of pixels over the 351 catchment, in a North-South direction and in an East-West direction respectively (Fig. 5). The 352 purpose of this is to monitor a possible influence of the slope over the generated runoff 353 scaling properties.

4) Implementation of the Multi-Hydro model on the Jouy-en-Josas catchment

4.1) Validation with raw radar data

The validation of the model is achieved by comparing the water height measured at the

361 Pont-de-Pierre gauge with the simulated one. Before going on authors would like to highlight that a proper validation on this case study is not possible given the available data, and will therefore limit this section to checking that the model approximately behaves well. The main

364 reasons for this problem are:

365 - Only one measuring point is available for the whole catchment taking into account 366 approximately an area of $2 \mathrm{~km}^{2}$.

367 - The uncertainty associated with this water level gauge is high. Indeed, it is not operated for 368 accurate hydraulic measurement but to trigger an alarm to evacuate a music school located nearby. The main issue is that the shape of the river bed cross section at this point is not 
available. The width was estimated at around $1.80 \mathrm{~m}$, using aerial photography from IGN and

371 an approximate measure from few meters away. In order to correctly model the pipe, we used

372 Multi-Hydro and tested various types of conduits. Finally, we chose to model the Bièvre as a

373 circular pipe, with free surface of $2 \mathrm{~m}$ diameter, which is close to the approximate

374 measurement. This choice is only an approximation which does not take into account the

375 variations in time of this shape due the fact that the bottom of the river bed is not flat and

376 contains moving rocks and changing vegetation.

377 - There is a lack of available data on initial soil saturation which is one of main sources of

378 uncertainty and can biased runoff (see Shah et al., 1996; Zehe et al., 2005) especially at the

379 beginning of the event. In this paper, dry conditions were considered at the beginning of each

380 event. A sensitivity test was conducted by considering a saturated soil at the beginning. A

381 slight increase (few percent) of simulated flow was noted only during approximately the first

382 hour (not shown here). Having longer rainfall time series would enable to simulate the

383 catchment's behaviour some time before the event and limit the uncertainties associated with

384 this issue.

385 - The uncertainties on the water input in the Bièvre River at the outlet the Bas-Près storage

386 basin upstream the catchment are not quantified.

387 - Obviously there are some uncertainties on the radar rainfall measurement itself.

388 The simulation and measurement at the "Pont de Pierre" point for the selected rainfall

389 events are displayed in Fig. 6. For the 09-02-2009 event we observe a clear overestimation at

390 the beginning of the event. For the 14-07-2010 event Multi-Hydro with the radar rainfall data

391 reproduces well the two main peaks, but overestimates the first local maximum of rainfall

392 intensity and misses the second one. The 15-08-2010 event shows a greater variability in the

393 first half of the simulation (variations are more pronounced on the model than on the

394 measurements) but reproduces well the last peak. Finally, for the 15-12-2011 event, the Multi- 
Hydro model reproduces well the first peak, but the flow decreases more rapidly than the observations.

Given the available data on a limited number of events it is difficult to attribute the observed discrepancies to one or several of the previously mentioned sources of uncertainty. Proper validation would indeed require the analysis of much longer time series and more accurate measurements with better position of sensors. Nevertheless, the obtained results do not highlight strikingly wrong behaviour of simulated water heights in conduit, and enable to partially reproduce observations. Finally, it seems that for some events the simulated flows might be too noisy compared with observed water levels. This should not affect the UM analysis that follows because the analyses carried out in this paper are spatial ones, i.e. maps are studied and not time series so the potential effect should be limited. Keeping in mind the previously mentioned limitations, results suggest that it remains relevant to use this implementation of Multi-Hydro with a rather coarse $10 \mathrm{~m}$ resolution for testing its sensitivity to small scale rainfall variability and analysing surface runoff with the help of multifractals.

The authors acknowledge that further investigations on other catchments with more accurately validated models would be needed to fully confirm the findings discussed after.

4.2) Uncertainty associated with small scales rainfall variability The envelop curves $\mathrm{Q}_{0.05}, \mathrm{Q}_{0.25}, \mathrm{Q}_{0.75}$, and $\mathrm{Q}_{0.95}$ are displayed in Fig. 7 for the 09-022009 event for 5 conduits selected from upstream to downstream, which enables to analyse the effect of the position of the conduit within the network. Link \#4 corresponds to the Pontde-Pierre measurement, and \#5 to the outlet of the catchment. As it can be seen in Fig. 7, link

417 \#4 and \#5 are located along the Bièvre River, and they take into account the significant base 418 flow in the river coming from upstream the Jouy-en-Josas catchment. It means that they are obviously less sensitive to local rainfall variability. Similar curves were also generated for 
water height (not shown) at the Pont-de-Pierre. The computed uncertainty is small and certainly does not explain the discrepancies between simulations and measurements noticed in Fig. 6, which are hence not simply due to effects of small scale rainfall variability. $C V_{95}^{\prime}$ and $C V^{\prime}{ }_{75}$ values computed for the selected conduits (Fig. 7) and the four events are displayed in Table 2. As expected they decrease while considering more and more downstream conduits. There is a sharp decrease in $C V^{\prime}$ when the Bièvre River is reached because the base flow of the river dampens the effect of local small scale rainfall variability occurring over the $3 \mathrm{~km}^{2}$ catchment, but the uncertainty only associated with this effect remains of roughly $10 \%$ at the outlet whatever the event. The values for up-stream and midstream pipes are great for all events, even for $C V^{\prime}{ }_{75}$ which highlights a significant impact of small scale rainfall variability on the simulated flow. The variability observed in the simulated flow is basically due to the disparities in the simulated downscaled rainfall fields which are transferred through the hydrological model (see Gires et al. 2012 for more detailed analysis of this issue). Small scale rainfall data is needed to understand better, and plan better, some local flooding due to sewer overflows which have been reported in some areas, notably the street parallel to the Bièvre River bed in the city (just North of it), There does not seem to have a straightforward relation between the computed uncertainty and the strength of the event (in terms of maximum rainfall peak intensity over $5 \mathrm{~min}$ ). Indeed, the tendency that could be observed on the 09-02-2010, 15-08-2010 and 15-12-2011 (not a linear one as for example the

439 peak rainfalls are equal to approximately 7 and $24 \mathrm{~mm} \cdot \mathrm{h}^{-1}$ for respectively the $15-08-2010$ and $440 \quad 15-12-2011$ event while the computed uncertainties are close) is not confirmed by the results 441 for the 14-07-2010 event (see Tab. 2). Finally, these values are comparable to the ones that 442 were obtained on a $1.5 \mathrm{~km}^{2}$ highly urbanised catchment located $40 \mathrm{Km}$ North-East on the 443 other side of the Paris area in Gires et al. (2014a). For this catchment, $C V^{\prime}{ }_{95}$ values were 444 ranging from 21 to $56 \%, 26$ to $94 \%$ and 22 to $50 \%$ from downstream to upstream for the same 
09-02-2009, 15-08-2010 and 15-12-2011 events respectively (at a different location). The

446 values are slightly smaller for this catchment and this is likely to be due to lower level of

447 imperviousness resulting in a smaller portion of rainfall becoming immediately active.

In this paper, the uncertainty is computed not only on the simulated flow, but also on the water depth in streets. As for the flow, for each realisation of downscaled rainfall field, the maximum water depth over the whole simulation is retrieved for each pixel. A sample is shown in Fig. 8.a for the 15-12-2011 event. The known hot spots are visible, although with too high values. For example, the modelled maximum water depth reaches more than $15 \mathrm{~cm}$ in the street along the Bièvre River bank in the city and the parallel street just north of it (already mentioned in the previous paragraph). Although some flooding is regularly reported by citizens to the SIAVB for these streets, such height was not reported for this event. In the urbanized portion of the catchment the street network is visible on the maximum water depth map, meaning the maximum values of water depth maps are reached on the corresponding pixels. Lower values are found on the on roads/streets located on the steep portion of the catchment because water moves faster in these areas. Same patterns and numerical values are 461 obtained for other realisations of the same event. Similar plots are obtained for the other 462 events with lower depths for the 09-02-2009 and 15-08-2010 (for which a lower cumulative rainfall depth was recorded) and greater depths for the 14-07-2010 event. Then, as for the

464 flow analysis previously carried out, the uncertainty on this maximum water depth is 465 computed with the help of the 5 and $95 \%$ quantiles for each pixel and a pseudo-coefficient of 466 variation. Illustrations of the quantiles maps are shown in Fig. 8.b and 8.c for the 15-12-2011 event. Similar patterns are observed on the two maps, notably for the hotspots previously mentioned which are visible on both maps. Maps of $C V^{\prime}{ }_{95}$ for maximum depth are displayed in Fig. 9 for the four rainfall events. It appears that the uncertainty is lower for the areas 
where the greatest maximum depths are found (i.e. on roads) and is also lower for the heaviest rainfall events. It reaches only few percents on the hottest points. The values (Fig. 9) are anyway much smaller than those found for sewer flow (Table 2 and Fig. 7). This apparent contradiction is likely to be due to the fact that most of the rain water is properly handled by sewers and overflows are limited for these events. It means that for these events disparities in local amounts will not be visible on ground levels, whereas they are indeed in sewer flows and water depths. Further investigations with heavier rainfall events should be carried out to confirm or not this interpretation. The areas with the greatest uncertainty are found in gardens for the weakest event (09-02-2009), and correspond to places with a very small maximum depth (smaller that $1 \mathrm{~mm}$ ), meaning that the hydrological relevance is not very high.

5) Multifractal characterization of overland water depth

Multifractal analyses of overland water depth during rainfall event are presented in this paper for the 14-07-2010 and 15-12-2011 events which are the two heaviest ones in terms of maximum rainfall intensity over 5 min (see Table 1).

Figure 10.a displays the spectral analysis of the water depth for the 14-07-2011 event. Maps of water depth for each time steps during the event are used to carry out 2D ensemble analyses. The quality of the scaling is low, with a coefficient of determination for the linear regression equal to 0.42 . The fact that the spectral slope is close to zero ( $\beta$ is found roughly equal to 0.2 ) indicates that the field is conservative, i.e. its mean is conserved across scales. It is therefore possible to implement directly on the field a Trace Moment (TM) analysis, which consists in assessing the validity of Eq. 4 by plotting it in log-log. Perfect UM fields would lead to straight lines. Figure 10.b shows the TM ensemble analysis performed over all the time steps of the same 14-07-2011 event. Two scaling regimes can be identified: a small 
scales regime from $10 \mathrm{~m}$ to $80 \mathrm{~m}$ (right part of Fig. 10.b) and a large scales regime from $80 \mathrm{~m}$ to $1280 \mathrm{~m}$ (left part of Fig. 10.b). The coefficient of determination $r^{2}$ of the linear regression for $q=1.5$ in Fig. $10 . \mathrm{b}$ is taken as an indication of the quality of the scaling. The scaling from small scales $(10 \mathrm{~m}-80 \mathrm{~m})$ is much more robust than for large scales ( $80 \mathrm{~m}$ to $1280 \mathrm{~m})$, as illustrated by the $r^{2}$ equal to respectively 0.99 and 0.91 . Given the low quality of the scaling 500 for large scales, UM parameter estimates will not be reported and discussed for this regime 501 because they are not reliable. Furthermore, small scales are crucial for surface runoff because 502 it is at these scales that it is generated into the drainage system. The location of this break at approximately $80 \mathrm{~m}$ indicates a possible physical interpretation. Indeed, it is the same location 504 as the break in the fractal analysis of the sewer network and corresponds roughly to the inter505 distance between roads. This would mean that this break is driven by the influence of the 506 collection of water by sewer network. The more robust scaling behaviour for surface flow is 507 found for the scales for which the sewer network does not behave yet as network but as isolated linear pipes. Before going on, it should be mentioned that numerous pixels have very small depth (see Fig. 8 for an illustration), for which the model uncertainties might be great. These zeros values or spurious ones close to zero will affect the scaling analysis for small 511 moments (typically q < 0.5) through a multifractal phase transition (see Gires et al., 2012, for a detailed analysis of this issue). Here the influence of this bias does not extend to moments close to 1 around which the estimates of UM parameters are carried out, meaning that they are 514 not affected by this issue. Although intrinsically less robust since scaling properties are statistical ones requiring numerous data to be properly observed, TM analyses were also carried out independently on each sampling time step of Multi-Hydro ( $3 \mathrm{~min}$ in this paper). The purpose is to see whether 
520 the temporal evolution of both the rainfall rate and the $r^{2}$ for $q=1.5$ in the TM analysis for the 521 two regimes identified in the ensemble analysis, i.e. small $(10 \mathrm{~m}-80 \mathrm{~m})$ and large scales (80 $\mathrm{m}-1280 \mathrm{~m})$. For this event, two rainfall peaks are observed, and they both result in a sudden loss of the scaling quality, more pronounced for large scales than small ones. For the first

524 peak (yellow bars on Fig. 11) the decrease of $r^{2}$ lasts approximately 20 min, while it lasts only 525 few minutes for the second peak (red bars on Fig 11). In both cases the quality of the scaling 526 behaviour improves again over few tens of minutes. The physical meaning of such loss is not 527 clear, but could be due to a bad representation of the surface flow process during intense 528 rainfall (it might take some time to retrieve a realistic surface flow simulation following a 529 sudden change in rainfall input), a bias in the geometrical repartition, or an intrinsic feature of 530 the process. For the latter, a possibility is that during intense rainfall period, the surface flow 531 exhibits more directly the rainfall features than its intrinsic ones which are retrieved once the 532 flow process has "adapted" to the new conditions. This would explain both the loss of scaling 533 quality and why scaling properties closer to rainfall ones are observed during these short 534 periods. Analysis with a higher resolution model would be needed to further investigate this 535 issue, which would also enable to have access to a wider range of small scales.

536 Similar features are retrieved for the other studied event (15-12-2011). Finally, it 537 should also be mentioned that similar results are also found when performing the analysis on 538 the North-South or West-East 1D-samples, which means that the preferential slope of the 539 catchment (North-South) does not seem to have an influence on the scaling features of the 540 simulated water depth. In terms of scaling quality, very similar results are also found with raw 541 radar data, or downscaled rainfall fields suggesting a limited impact of small scale rainfall 542 variability on these features. The same downscaling process as in section 2 is used. 
545 scales, and are displayed in Table 3 for the two events (14-07-2011 and 15-12-2012) and for

546 simulations with raw radar data and also a realisation of downscaled rainfall field with $\alpha=1.8$

547 and $C_{1}=0.1$ (other realisations yield very similar results). The temporal evolutions of $\alpha$ and $C_{1}$

548 for the 14-07-2011 event are shown in Figures 12.

549 It appears that the UM parameters are also affected by the "jumps" that were noticed

550 on $r^{2}$ in Fig. 11. Indeed after an intense period, sharp increase of $\alpha$ and decrease of $C_{1}$ are

551 noticed. These pronounced variations mean that the values obtained with ensemble analyses

552 should not be over-interpreted. Nevertheless few comments can be made. First the values of

$553 C_{1}$ are much greater than the ones reported for rainfall (typically $0.1-0.3$ at small scale)

554 meaning that significant levels of water depth are much more concentrated than the rainfall

555 field, which reflects the influence of the physical processes associated with surface flow on

556 the transferred field, notably the flow concentration. The most relevant one is the topography

557 that routes water through specific paths and tends to concentrate it. Second the values of UM

558 parameters are quite different between the two events. These differences are much greater

559 than the ones observed on the rainfall fields (see Ichiba, 2016, for a detailed analysis of these

560 storms) at small scales. This suggests that the large scales rainfall pattern has a strong

561 influence on the retrieved parameters. Indeed, the topography and small scale rainfall features

562 are the same between the two simulations; the only difference is the large scale rainfall

563 features. Thirdly the values of $\gamma_{\mathrm{s}}$ are rather similar for both events (the differences between $\alpha$

564 and $C_{1}$ tend to compensate themselves).

565 The temporal evolutions of the UM parameters obtained by inputting raw and

566 downscaled rainfall data are very similar. The differences are slightly more pronounced on the

567 values computed on ensemble analysis but as previously said this should not be over-

568 interpreted given the strong variations visible in the temporal analysis. This similarity 
highlights the low influence of small scale rainfall variability on the retrieved parameters

570 which seems to be more dependent on features associated with surface flow process itself or $571 \quad$ large scale rainfall.

In order to test the sensitivity of the results to small scales rainfall features, synthetic

rainfall fields with various sets of known parameters are used as input to Multi-Hydro simulations. More precisely the pseudo-events tested last 30 min with an average intensity of $10 \mathrm{~mm} / \mathrm{h}$. Three pairs $\left(\alpha ; \mathrm{C}_{1}\right)$ of parameters are tested: $(1.8 ; 0.1),(1.8 ; 0.05),(1.4 ; 0.1)$. Figure 13 displays the temporal evolutions of the rain rates, $r^{2}, \alpha$ and $C_{1}$ for water depth for the three synthetic rainfall events.

The temporal evolution shows the same general tendency as the one observed with the real events. A loss of scaling quality is observed during the event itself, and it improves afterwards. $\alpha$ and $C_{1}$ have a constant behaviour during the rainfall, while they decrease and increase respectively after the rainfall has stopped. The comparison of the UM parameters for the overland maximum water depth shows that they do not seem to depend on the small scale rainfall variability in this case. $\alpha$ is constant around 1.4 while $C_{l}$ is constant around 0.6 during the rainfall. $\gamma_{\mathrm{s}}$ is again constant around 1.7 on average. The rainfall UM parameters do not seem to modify the structure of the overland flow, and its geometrical distribution. Successive simulations with the same parameters for synthetic rainfall yielded same results. A physical explanation of the $C_{1}$ parameter could be that during the rainfall, the surface flow is more homogenous due to a ubiquitous input of water. UM parameters on water depth are thus closer to the rainfall ones (small $C_{1}$ ). However after the rain has stopped, the disparities of simulated water depth are increased due to predominant pathways (roads) or topographic depressions where the water can accumulate. The greater $C_{1}$ after the event could reflect this 
fact. The smaller values of $\alpha$ mean that the disparities among the areas where water remains tend to decrease after the rainfall event.

This study seems to highlight the fact that UM parameters $\alpha$ and $C_{l}$ for water depth are rather relying on the large scale structure of the rainfall and on the catchment features, while 597 the maximum observable singularity $\gamma_{\mathrm{s}}$ is conserved for all events. Further studies could 598 infirm or confirm the fact that $\gamma_{\mathrm{s}}$ depends on the studied catchment. The temporal evolutions 599 of the UM parameters also deeply rely on the rainfall rate. Synthetic events with block structures enabled to stand out rather simple general tendencies. They become more complex 601 with real rainfall, when the intensity has a higher temporal variability.

602 The temporal evolutions of the UM parameters also enable to quantify a catchment 603 response time. Due to the sampling time step of the simulations, the uncertainty associated 604 with the response is of $3 \mathrm{~min}$. Still, it can be noted that in urban catchments (or semi-urban 605 here), the response time of water depth UM parameters to the beginning of a rainfall or to an 606 important peak of intensity is almost non-existent. This is due to the presence of impervious 607 area over which rainfall directly transfer into surface runoff.

608

6) Conclusions

The Multi-Hydro model was implemented on the Jouy-en-Josas catchment in the Paris area. This $3 \mathrm{~km}^{2}$ semi-urbanised catchment exhibits sharp slopes, and a dense area along the Bièvre River bed. It has often been damaged by major pluvial and fluvial flooding, before the construction of storage basins along the river path. The model was validated on this new catchment on four rainfall events with the help of the data from a height gauge near the outlet.

617 Rainfall radar data with a resolution of $1 \mathrm{~km} \times 1 \mathrm{~km} \times 5 \mathrm{~min}$ was used. 
619 the model outputs to small scales unmeasured rainfall variability, i.e. occurring below the

620 resolution of the available raw radar data. It appears that it is rather significant on flow

621 simulated in conduits with pseudo coefficients of variations ranging from $90 \%$ upstream to

$62210 \%$ downstream. This confirms previous results obtained on a $1.5 \mathrm{~km}^{2}$ flat highly urbanised

623 catchment also in the Paris area. The methodology was extended here to simulated water

624 depth, and it was found that the sensitivity was much lower than for conduits' flow. This is

625 likely to be due to the fact that the sewer system is mainly able to cope with the storm water

626 for these events limiting the amount of surface runoff.

627 After using them to downscale the radar data, Universal Multifractals are used in an

628 innovative way to characterize the surface flow process -through simulated water depth for

629 each $10 \mathrm{~m}$ x $10 \mathrm{~m}$ pixel over 3 min time steps- during rainfall events. UM parameters $\alpha$ and

$630 C_{1}$, and the composite parameter $\gamma_{\mathrm{s}}$ are evaluated on the outputs of Multi-Hydro. Two scaling

631 regimes are identified for this field and estimates are only reliable for small scales, i.e. 10m -

$63280 \mathrm{~m}$, and related to the fractal feature of the sewer system which exhibits a scale break at the

633 same scale. There is a loss of the quality of the scaling during intense rainfall periods and UM

634 parameters get closer to rainfall ones. A possible interpretation is that during this short period,

635 a mixture of the scaling behaviour of both surface flow and rainfall is observed. After the

636 event scaling is improved and features more specific to surface flow processes are retrieved

637 with a field strongly concentrated and variability among the wet areas dampened $\left(C_{1}\right.$ greater

638 than 1 and $\alpha$ smaller than 1). Small scale rainfall features do not seem to strongly influence

639 the results which depend more on large scales rainfall spatio-temporal patterns for these

640 events which do not trigger much sewer overflow.

641 The conclusions found with the help of this innovative methodology are not as

642 straightforward as the authors would have hoped. Further investigations with other rainfall 
643 events, other catchments, notably with denser monitoring network including in-sewer

644 measurements, should be carried out to strengthen the results. Higher resolution models

645 should also be tested to extend the range of available scales for the small scales regime to

646 obtain more reliable estimates of scaling features. Such new analysis would enable to

647 generalize the behaviour of the scaling and of the UM parameters which describes the surface

648 flows, and eventually to link them to other geometrical features of the catchment, such as the

649 fractal dimension of its impervious surface, of the roads (which are the preferential path for

650 surface flows) or of the sewer system. This paper should be seen as a promising first step that

651 hints at innovative techniques relying on scale invariance properties to analyse how the

652 rainfall extremes are either dampened or enhanced by hydrological models and also to

653 quantify the extremes at very high spatial resolution (typically $1 \mathrm{~m}$ ) without having to run the

654 model at these resolutions which would require too much time especially for real time

655 applications.

656

657

658 Acknowledgments

659 Authors acknowledge partial financial support from the European Interreg IV RainGain

660 project (www.raingain.eu), the Chair "Hydrology for resilient cities" endowed by Veolia, and

661 the Ile-de-France regional R2DS RadX@IdF project. Authors would also like to thank Hervé

662 Cardinal from the SIAVB for providing data and fruitful discussions.

663

664

665

666 6) References

667 
(EEA), E.E.A., 2014. http://www.eea.europa.eu/articles/analysing-and-managing-urbangrowth (consulted on 20-10-2014).

Bolle, A. et al., 2006. Hydraulic modelling of the two-directional interaction between sewer and river systems, Urban Drainage Modelling and Water Sensitive Urban Design, Merlbourne.

Carr, R.S. and Smith, G.P., 2006. Linking of 2D and Pipe hydraulic models at fine spatial scales, Urban Drainage Modelling and Water Sensitive Urban Design, Melbourne, Australia.

Chen, A.S., Djordjević, S., Leandro, J. and Savić, D.A., 2007. The urban inundation model with bidirectional flow interaction between 2D overland surface and 1D sewer networks, Proceedings of NOVATECH, Lyon, France.

Deltares, 2013. Sobek Suite V2.13, Deltares, Delft, NL.

Despotovic, J., Plavsic, J., Stefanovic, N., Pavlovic D., 2005. Inefficiency of storm water inlets as a source of urban floods. Water Sci Technol, 15(2):139-145

Djordjevic, S., Prodanovic, D. and Maksimovic, C., 1999. An approach to simulation of dual drainage. Water Science and Technology, 39(9): 95-103.

Djordjević, S., Prodanović, D., Maksimović, Č., Ivetić, M., Savić D., 2005. SIPSON Simulation of Interaction between Pipe flow and Surface Overland flow in Networks. Water Science and Technology, 52 (5): 275-283.

Douglas, E.M. and Barros, A.P., 2003. Probable maximum precipitation estimation using multifractals: Application in the eastern United States. Journal of Hydrometeorology, 4(6): 1012-1024.

El Tabach, E., Tchiguirinskaia, I., Mahmood, O. and Schertzer, D., 2009. Multi-Hydro: a spatially distributed numerical model to assess and manage runoff processes in peri- 
urban watersheds, Final conference of the COST Action C22 Urban Flood Management, Paris 26/27.11.2009, France.

Fletcher, T.D., Andrieu, H. and Hamel, P., 2013. Understanding, management and modelling of urban hydrology and its consequences for receiving waters: A state of the art. Advances in Water Resources, 51(0): 261-279.

Giangola-Murzyn, A. et al., 2014. Multi-Hydro : an open access coupling model for urban hydrology (submitted). Journal of Hydro-Informatics.

Gires, A., Schertzer, D., Tchiguirinskaia, I., Lovejoy, S., Maksimovic, C., Onof, C., Simoes, N., 2011b. Impact of unmeasured rainfall variability on urban discharge: a case study in a multifractal framework. Houille Blanche - Revue Internationale de l'Eau(4): $37-$ 42.

Gires, A., Tchiguirinskaia, I., Schertzer, D. and Lovejoy, S., 2012. Influence of the zerorainfall on the assessment of the multifractal parameters. Advances in Water Resources, 45, 13-25.

Gires, A., Tchiguirinskaia, I., Schertzer, D. and Lovejoy, S., 2013. Multifractal analysis of a semi-distributed urban hydrological model. Urban Water Journal, 10(3): 195-208.

Gires, A. et al., 2014a. Impacts of small scale rainfall variability in urban areas: a case study with 1D and 1D/2D hydrological models in a multifractal framework. Urban Water Journal: 1-11.

Gires, A. et al., 2014b. Influence of small scale rainfall variability on standard comparison tools between radar and rain gauge data. Atmospheric Research, 138(0): 125-138.

Gires, A., Tchiguirinskaia, I., Schertzer, D., Ochoa-Rodriguez, S., Willems, P., Ichiba, A., Wang, L.-P., Pina, R., Van Assel, J., Bruni, G., Murla Tuyls, D., and ten Veldhuis, M.-C., 2017. Fractal analysis of urban catchments and their representation in semi- 
distributed models: imperviousness and sewer system, Hydrol. Earth Syst. Sci., 21, 2361-2375, https://doi.org/10.5194/hess-21-2361-2017.

Hsu, M.H., Chen, S.H. and Chang, T.J., 2000. Inundation simulation for urban drainage basin with storm sewer system. Journal of Hydrology, 234(1-2): 21-37.

Hubert, P. et al., 1993. Multifractals and extreme rainfall events. Geophys. Res. Lett., 20: 931-934.

Ichiba, A. (2016). X-band radar data and predictive management in urban hydrology, Ph.D. thesis, Université Paris-Est.

Ichiba, A., Gires, A., Tchiguirinskaia, I., Schertzer, D., Bompard, P., and Ten Veldhuis, M.C., 2017. Scale effect challenges in urban hydrology highlighted with a distributed hydrological model, Hydrol. Earth Syst. Sci., accepted.

Innovyze, 2012. InfoWorks CS v13.0.6.

Innovyze, 2013. Infoworks ICM v.3.5.

Institute, D.H., 2011. Mike Urban.

IPCC, 2013. Working Group 1 contribution to the IPCC fifth report climate change 2013: the physical science basis, summary of policy makers. Technical report.

Jankowfsky, S., 2011. Understanding and modelling of hydrological processes in small periurban catchments using an object-oriented and modular distributed approach. Application to the Chaudanne and Mercier sub-catchments (Yzeron catchment, France). PhD Thesis., Lyon, France.

Parisi, G. and Frish, U., 1985. A multifractal model of intermittency. In: M. Ghill, R. Benzi and G. Parisi (Editors), Turbulence and predictability in geophysical fluid dynamics. Elsevier North Holland, New-York, pp. 111-114. 
Phillips, B., Yu, S., Thompson, G. and Silva, N., 2005. 1D and 2D Modelling of Urban Drainage Systems using XP-SWMM and TUFLOW, 10th International Conference on Urban Drainage, Copenhagen, Denmark.

Pitt, M., 2008. The Pitt Review : Learning lessons from the 2007 floods, http://webarchive.nationalarchives.gov.uk/20100807034701/http:/archive.cabinetoffic e.gov.uk/pittreview/thepittreview/final_report.html (accessed 20-10-2014).

Richard, J., Giangola-Murzyn, A., Gires, A., Tchiguirinskaia, I. and Schertzer, D., 2014. Gis data Assimilation interface for distributed hydrological models. Environmental Modelling and Software (submitted).

Rodriguez, F., Andrieu, H. and Morena, F., 2008. A distributed hydrological model for urbanized areas - model development and application to case studies. Journal of Hydrology, 351: 268-287.

Rossman, L.A., 2010. Storm Water Management Model, User's Manual. Version 5.0. U.S. Environmental Protection Agency, EPA/600/R-05/040.

Royer, J.-F., Biaou, A., Chauvin, F., Schertzer, D. and Lovejoy, S., 2008. Multifractal analysis of the evolution of simulated precipitation over France in a climate scenario. C.R Geoscience, 340: 431-440.

Schertzer, D. and Lovejoy, S., 1987. Physical modelling and analysis of rain and clouds by anisotropic scaling and multiplicative processes. J. Geophys. Res., 92(D8): 96939714.

Schertzer, D. and Lovejoy, S., 2011. Multifractals, generalized scale invariance and complexity in geophysics. International Journal of Bifurcation and Chaos, 21(12): 3417-3456. 
Shah, S.M.S., O'Connell, P.E. and Hosking, J.R.M., 1996. Modelling the effects of spatial variability in rainfall on catchment response. 1. Formulation and calibration of a stochastic rainfall field model. Journal of Hydrology, 175(1-4): 67-88.

Solution, X., 2012. XPSWMM V.12.

Tabary, P., 2007. The new French operational radar rainfall product. Part I: Methodology. Weather and Forecasting, 22(3): 393-408.

Tabary, P. et al., 2007. The new French operational radar rainfall product. Part II: Validation. Weather and Forecasting, 22(3): 409-427.

Velleux, M.L., England, J.F. and Julien, P.Y., 2011. TREX Watershed Modelling Framework User's Manual: Model Theory and Description. Department of civil engineering, Colorado State University, Fort Collins: 106p.

Tables:

\begin{tabular}{|l|l|l|l|l|}
\hline & Radar rain depth & Rain gauge depth & & \multicolumn{1}{c|}{ Peak } \\
& $(\mathrm{mm})$ & $(\mathrm{mm})$ & Duration (min) & intensity \\
& & & & over 5 min \\
& & & & \\
\hline $09-02-2009$ & 9.4 & Unavailable $/ \mathrm{h})$ & 725 & 5.12 \\
\hline $14-07-2010$ & 43.2 & 35.2 & 1020 & 52.06 \\
\hline $15-08-2010$ & 27.8 & 20.8 & 1745 & 24.26 \\
\hline $15-12-2011$ & 26.2 & 29.6 & 785 & \\
\hline
\end{tabular}

Table 1: Main features for the four studied rainfall events. Cumulative depth are computed over the whole event. For the radar data averages over the catchment are displayed. 


\begin{tabular}{|l|l|l|l|l|l|}
\hline Event / Link & $\# 1$ & $\# 2$ & $\# 3$ & $\# 4$ & $\# 5$ \\
\hline $09-02-2009$ & $63 / 16$ & $35 / 15$ & $10 / 7.2$ & $4.0 / 1.7$ & $4.8 / 2.1$ \\
\hline $14-07-2010$ & $76 / 22$ & $27 / 13$ & $7.1 / 3.6$ & $7.5 / 3.2$ & $7 / 3.1$ \\
\hline $15-08-2010$ & $70 / 20$ & $38 / 16$ & $26 / 12$ & $9.3 / 3.9$ & $8.5 / 3.8$ \\
\hline $15-12-2011$ & $60 / 23$ & $50 / 22$ & $28 / 12$ & $11 / 4.1$ & $8.7 / 3.9$ \\
\hline
\end{tabular}

Table 2: $C V_{95}^{\prime}$ and $C V^{\prime}{ }_{75}$ in \% (first and second figure respectively) for the five selected

783 conduits and four rainfall events.

\begin{tabular}{|l|l|l|l|l|}
\hline Event & Rainfall input & $\alpha$ & $C_{1}$ & $\gamma_{\mathrm{s}}$ \\
\hline 14-07-2010 & Raw radar data & 1.55 & 0.62 & 1.52 \\
\cline { 2 - 5 } & Downscaled rainfall & 1.25 & 0.90 & 1.68 \\
\hline 15-12-2011 & Raw radar data & 0.95 & 1.42 & 1.74 \\
\cline { 2 - 5 } & Downscaled rainfall & 0.99 & 1.22 & 1.65 \\
\hline
\end{tabular}

Table 3: UM parameters for small scales $(10 \mathrm{~m}-80 \mathrm{~m})$ computed with the help of a 2D

analysis with either raw radar data or a realisation of downscaled rainfall field (with $\alpha=1.8$ and $\left.C_{1}=0.1\right)$ as rainfall input for the 14-07-2010 and 15-12-2011 events. 
Figure captions:

796

797
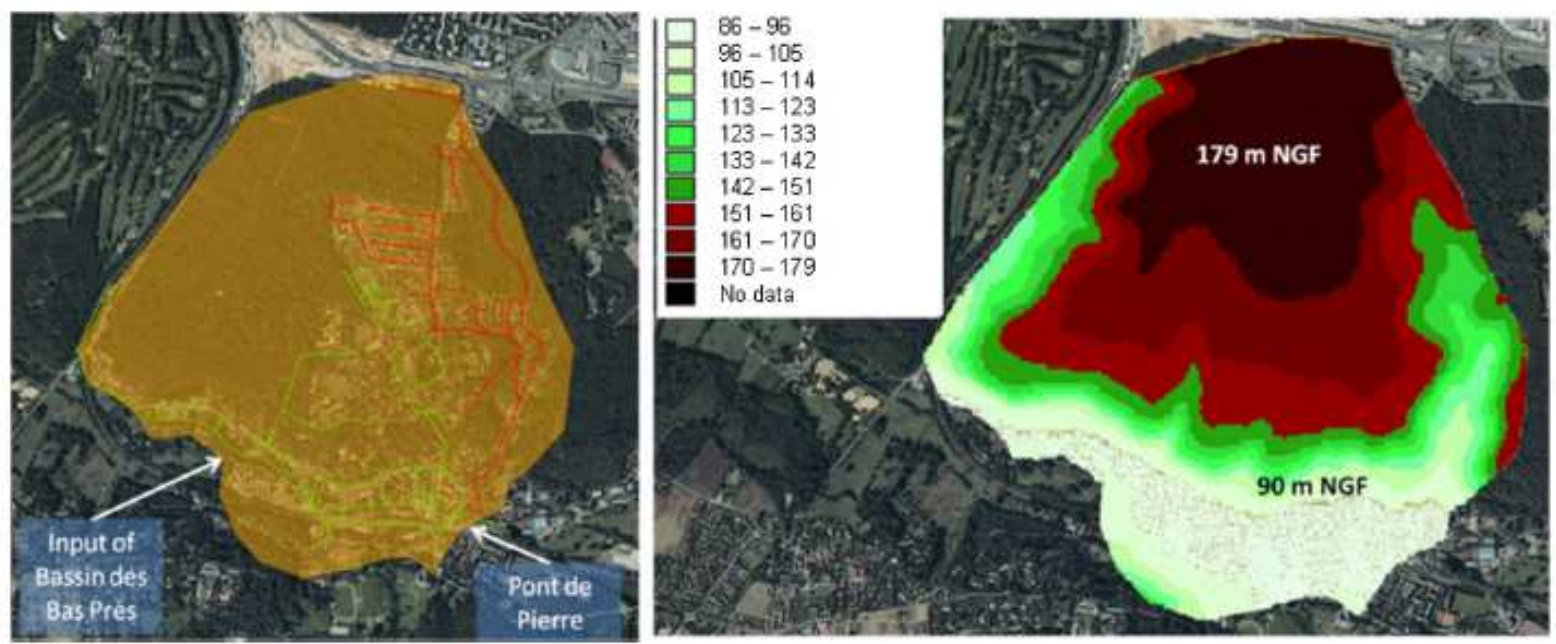

799 Figure 1: Maps of the Jouy-en-Josas catchment: (left) aerial photography and sewer system

800 (The green portion of the sewer network corresponds to the portion over which validation is 801 possible), (right) elevation in $\mathrm{m}$.

802
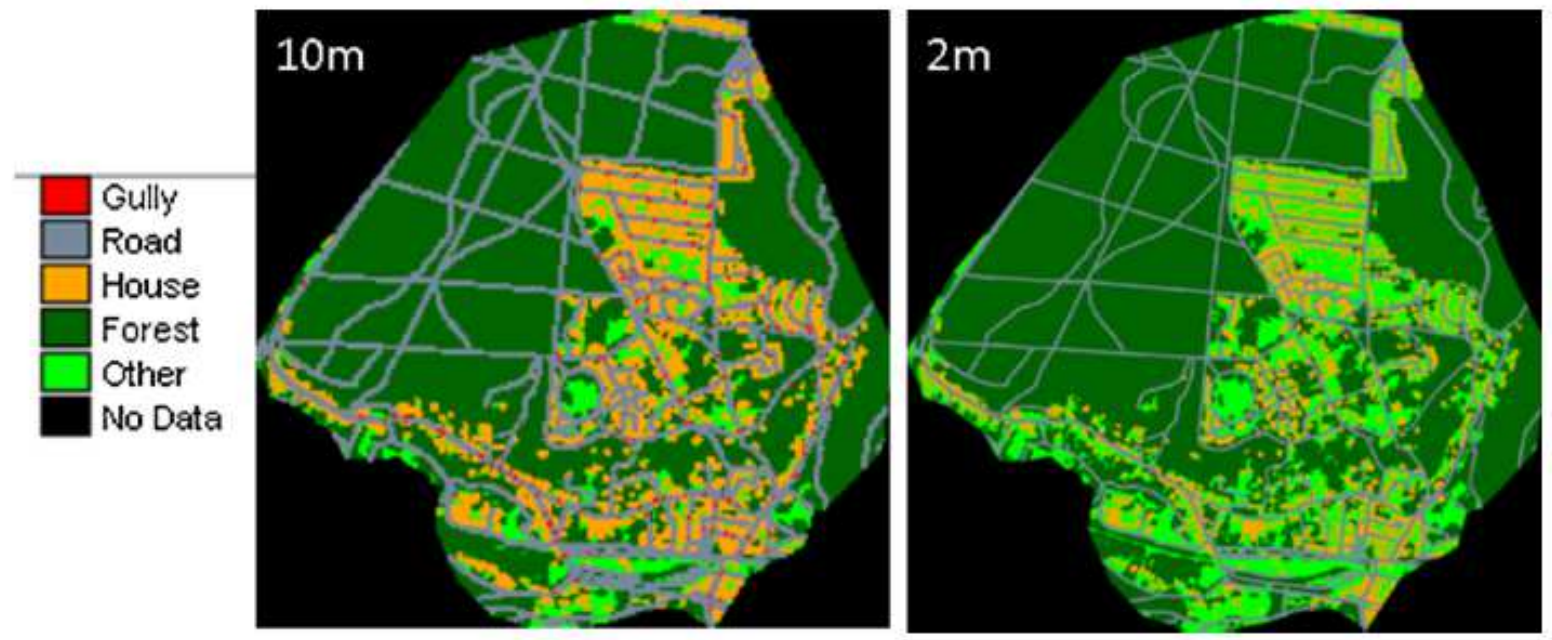

803 Figure 2: Map of the land use obtained with the help of MH-AssimTool over the Jouy-en-

804 Josas catchment for two different resolutions. 

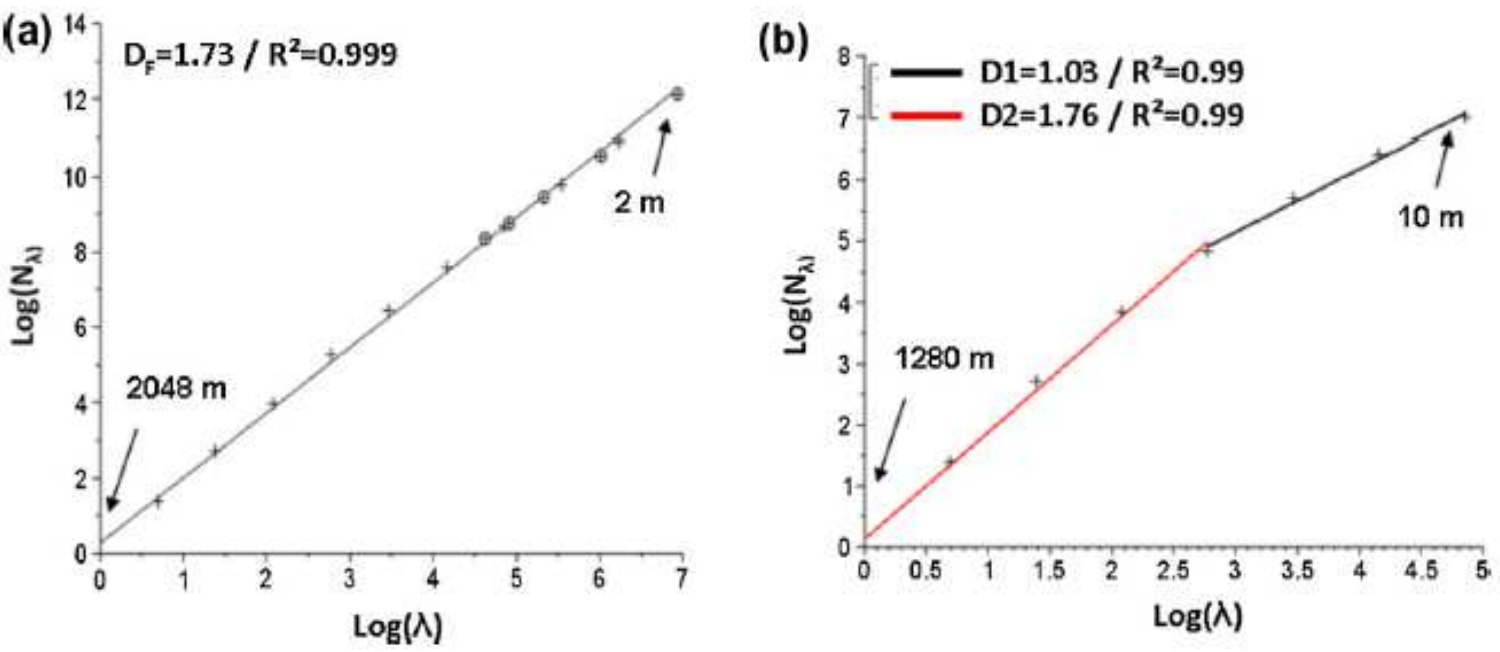

805

806 Figure 3: (a) Evaluation of the fractal dimension of the impervious area for the studied

807 catchment (Eq. 1 in log-log plot). The circle points correspond to the figures obtained from

808 the map generated with the help of MH-AssimTool at various resolutions. (b) Evaluation of

809 the fractal dimension of the sewer system.

810 

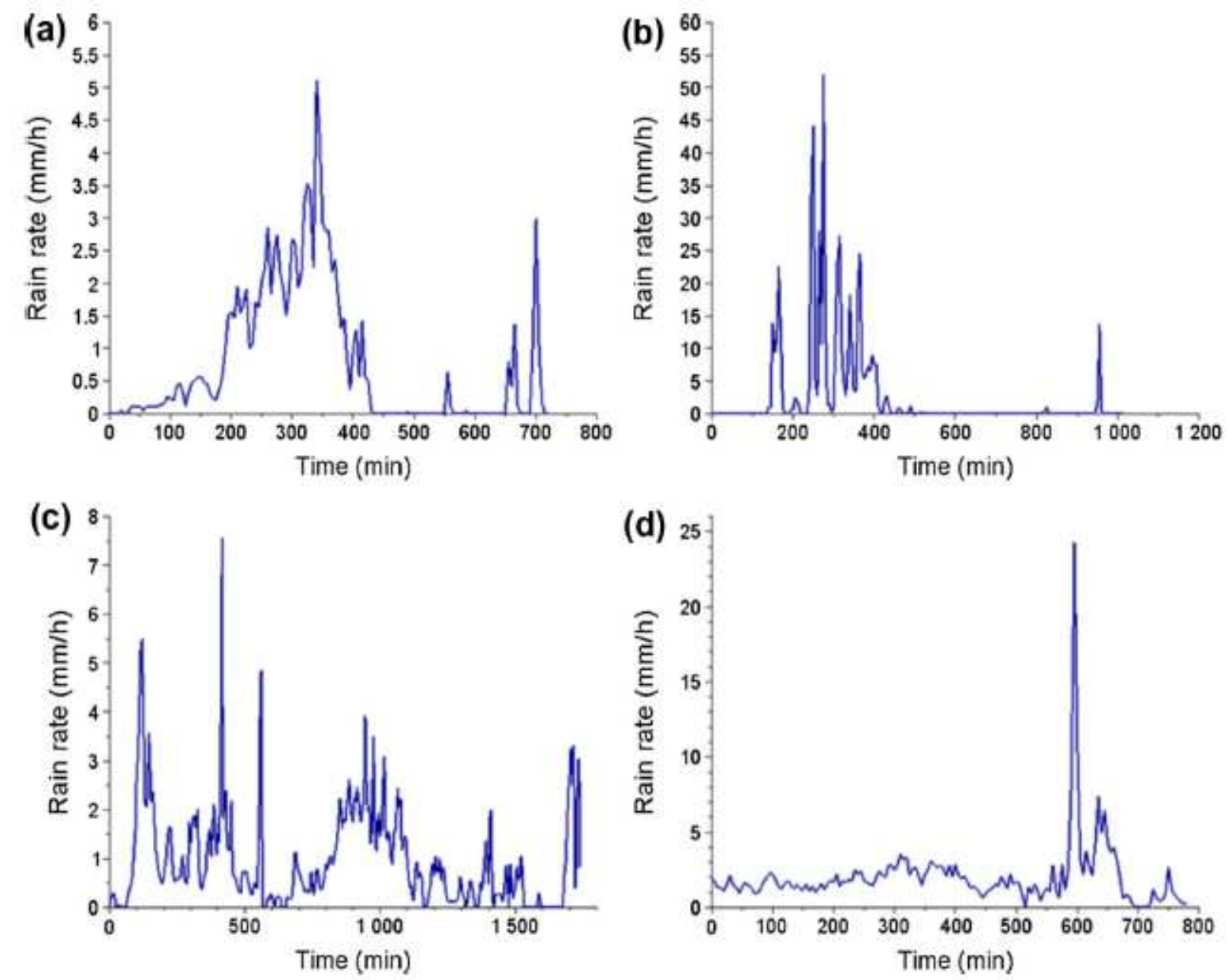

812 Figure 4: Average over the catchment of the rainfall radar intensity in $\mathrm{mm} / \mathrm{h}$ over 5 min time

813 steps for the four events: (a) 09-02-2009, (b) 14-07-2010, (c) 15-08-2010, (d) 15-12-2011
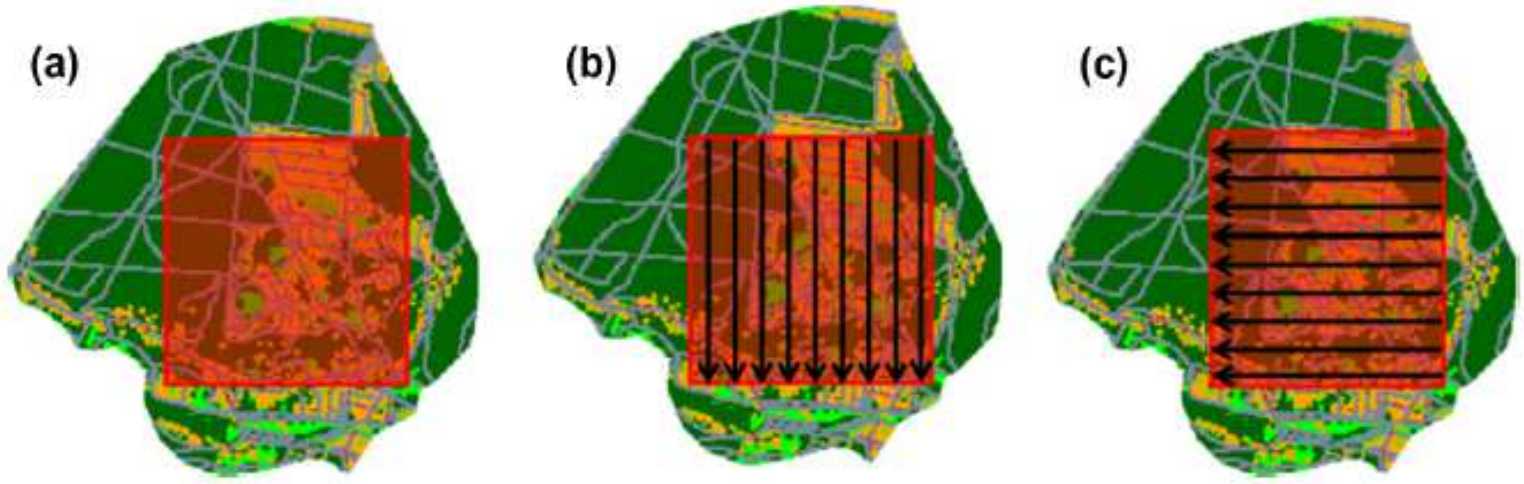

815 Figure 5: Illustration of the samples studied in the multifractal analysis of overland water

816 depth at the end of each 3-min Multi-Hydro loop: (a) 2D maps, (b) 1D vertical columns (N-S

817 direction), (c) 1D horizontal rows (W-E direction). 

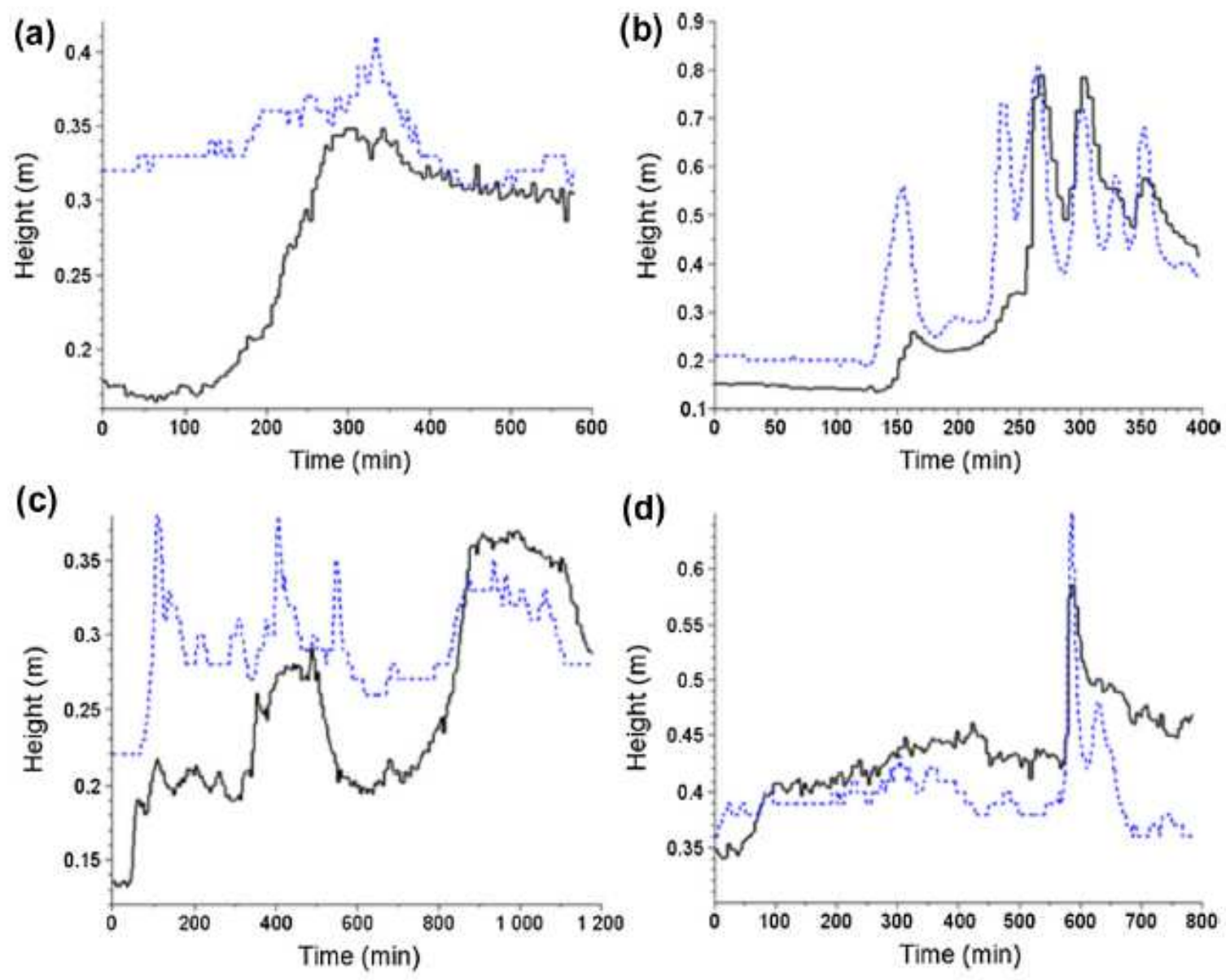

\section{Measurements}

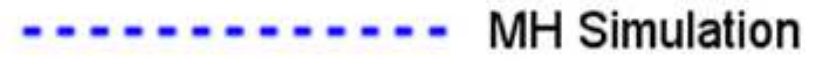

819 Figure 6: Water height simulated with the help of Multi-Hydro using raw radar data as rainfall

820 input, and measurements at the Pont-de-Pierre for the four events: (a) 09-02-2009, (b) 14-07-

8212010, (c) 15-08-2010, (d)15-12-2011 


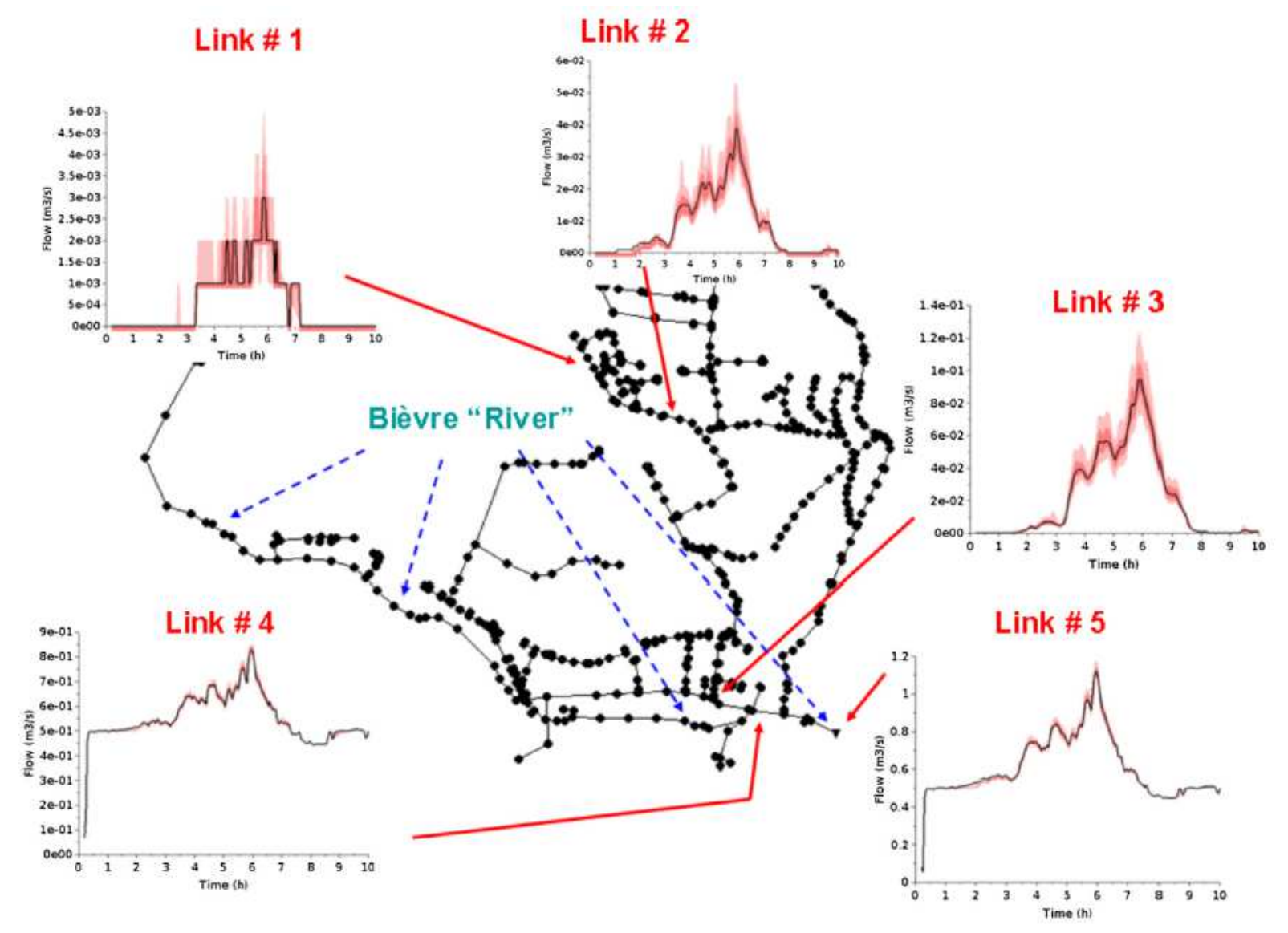

823 Figure 7: Simulated flow with the raw radar data (black), $Q_{0.25}$ and $Q_{0.75}$ (dark pink colour),

$824 Q_{0.05}$ and $Q_{0.95}$ (light pink colour) for 5 conduits of the studied catchment for the 09-02-2009 825 event.

(a) a realisation

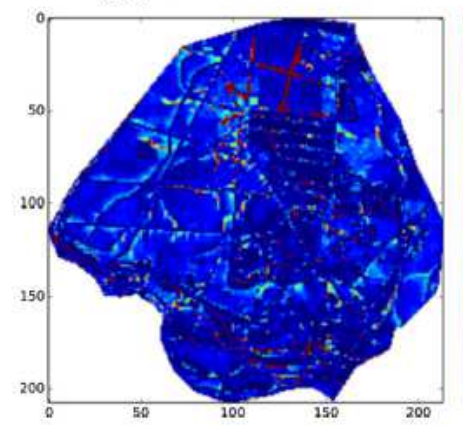

(b) $5 \%$ quantile

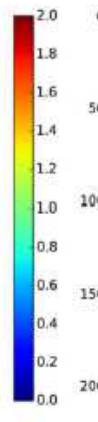

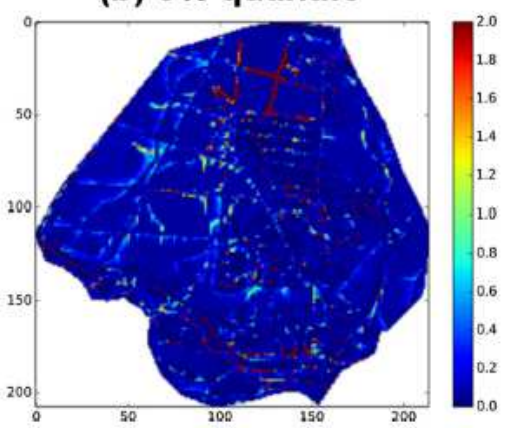

(c) $95 \%$ quantile

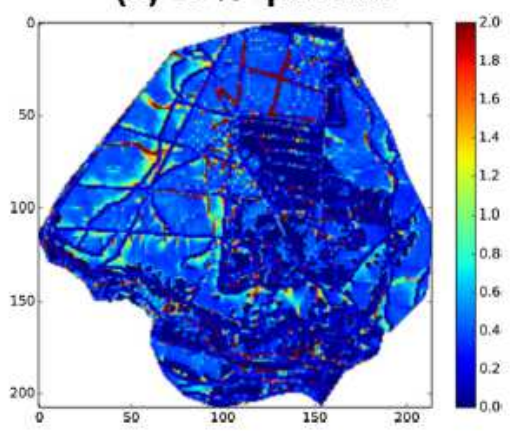

827 Figure 8: For the 15-12-2011 event. (a) Map of the computed maximum water depth for a

828 realisation of the downscaled rainfall field. (b) 5\% quantile map of the maximum water depth

829 over 100 realisations. (b) $95 \%$ quantile map of the maximum water depth over 100

830 realisations. Unit is $\mathrm{m}$. 
(a) 09-02-2009

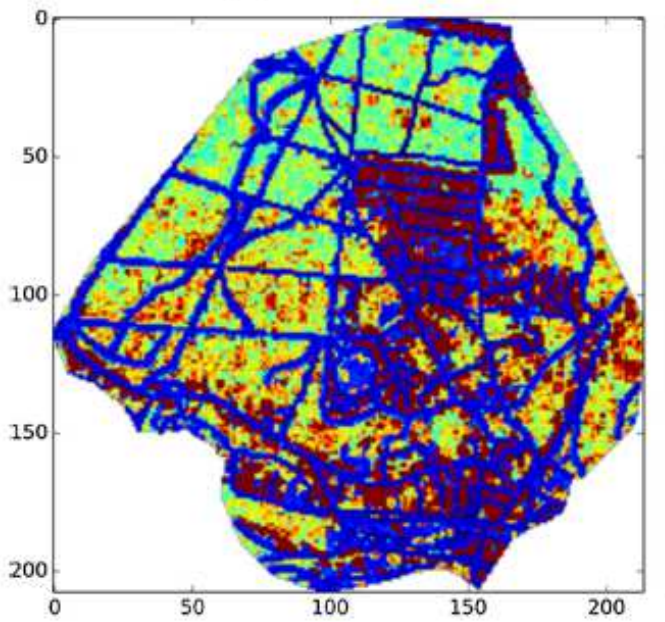

(c) 15-08-2010

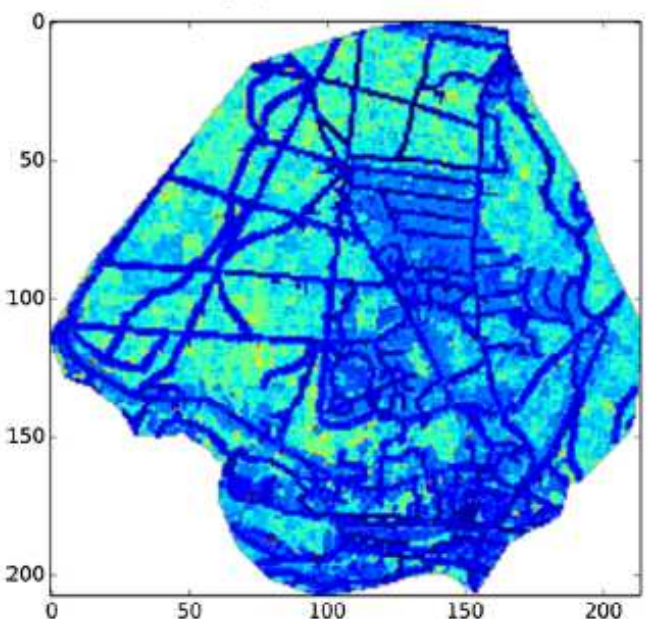

(b) 14-07-2010
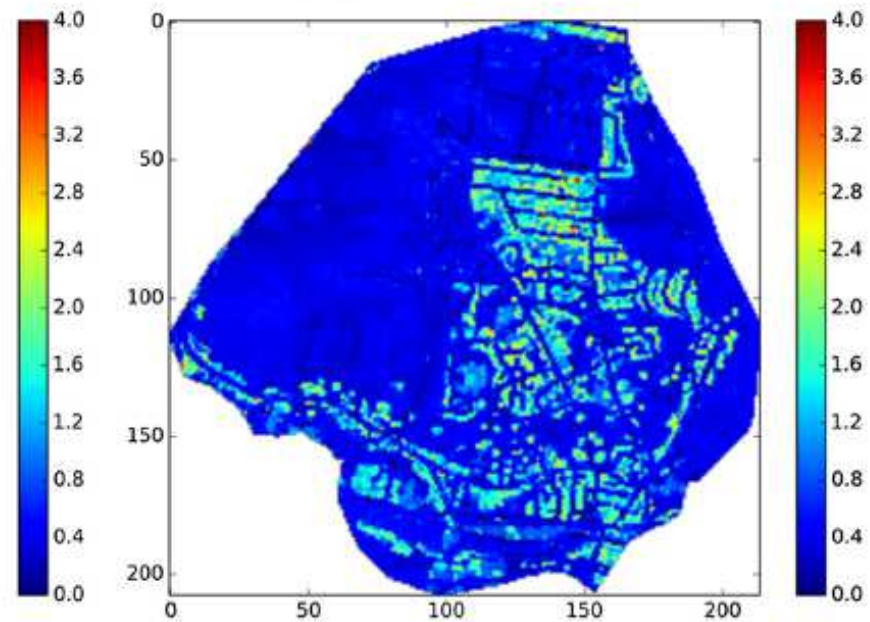

(d) 15-12-2011

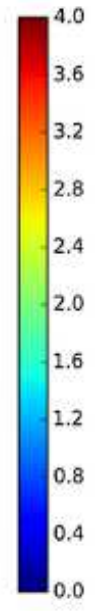

Figure 9: Map of $C V^{\prime}{ }_{95}$ (in \%) for the maximum water depth for the 09-02-2009 (a), 15-08-

8332010 (b) and 15-12-2011 (c) events. 
(a)

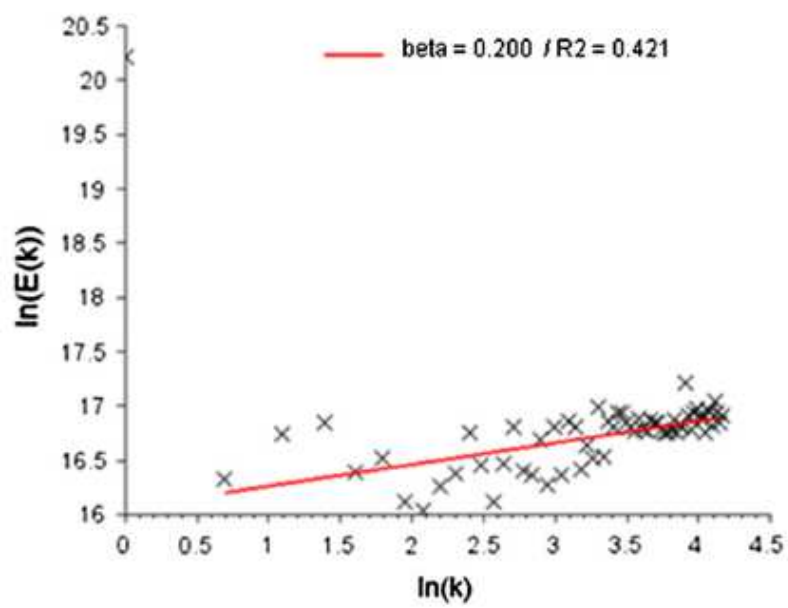

(b)

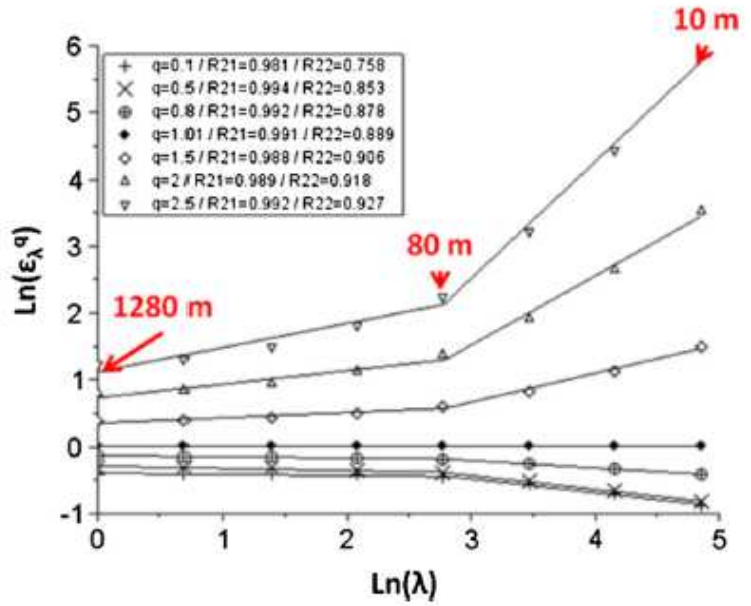

835

836 Figure 10: For the 14-07-2010 event and 2D ensemble analysis over all the time steps: (a)

837 Spectral analysis, i.e. Eq. 5 in log-log plot; (b) TM analysis, i.e. Eq. 3 in log-log plot.

(a)

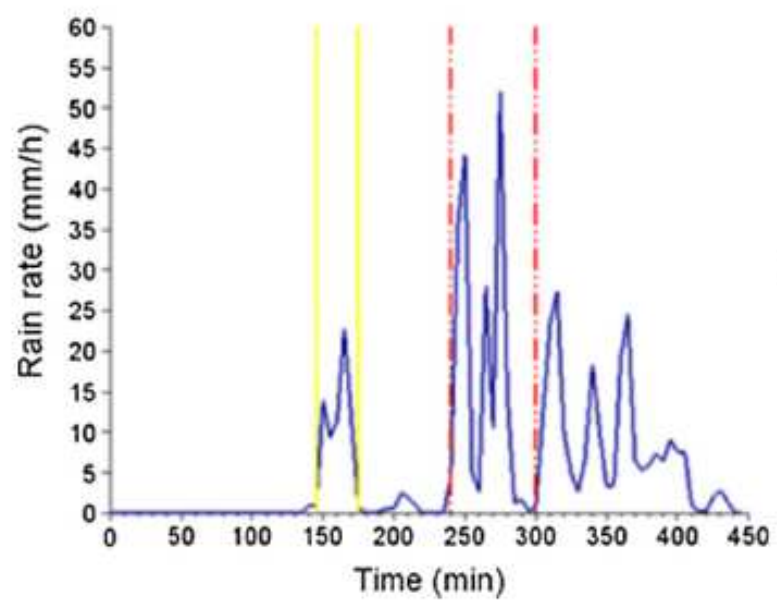

(b)

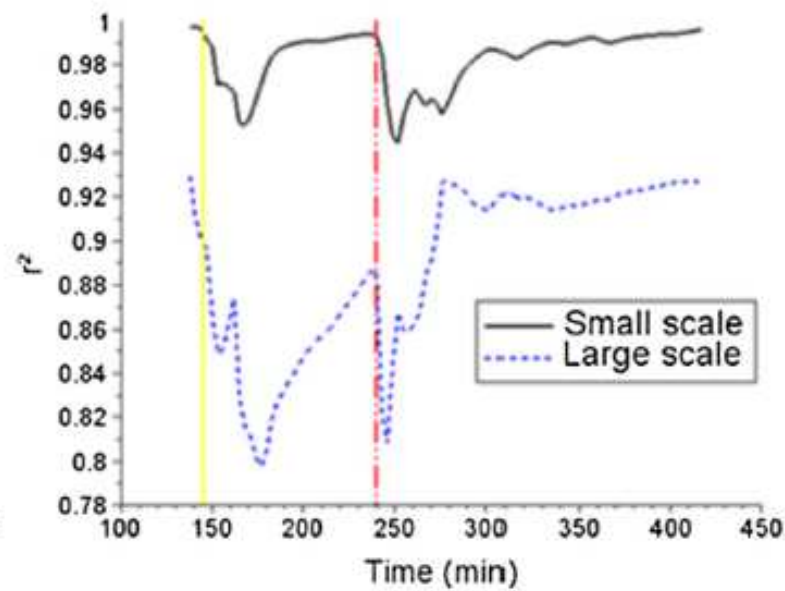

838

839 Figure 11: For the 14-07-2010 event: (a) Temporal evolution of the rain rate; (b) Temporal

840 evolution of the $r^{2}$ for $q=1.5$ in the TM analysis for the two regimes identified in Fig. 10. 

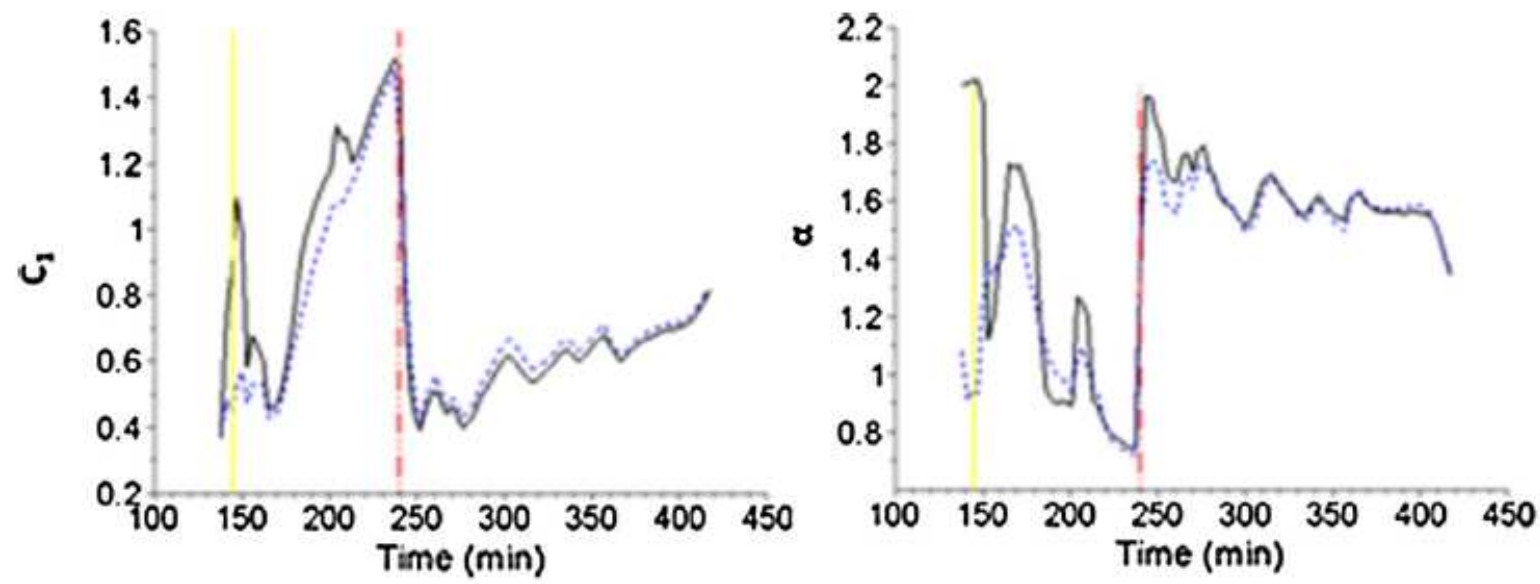

841

\section{Raw data}

Downscaled data

842 Figure 12: Temporal evolution of the UM parameters $\alpha$ and $C_{1}$ of the maximum water depth

843 field over $3 \mathrm{~min}$ for small scales $(10-80 \mathrm{~m})$ for the 14-07-2010 rainfall event.

844 

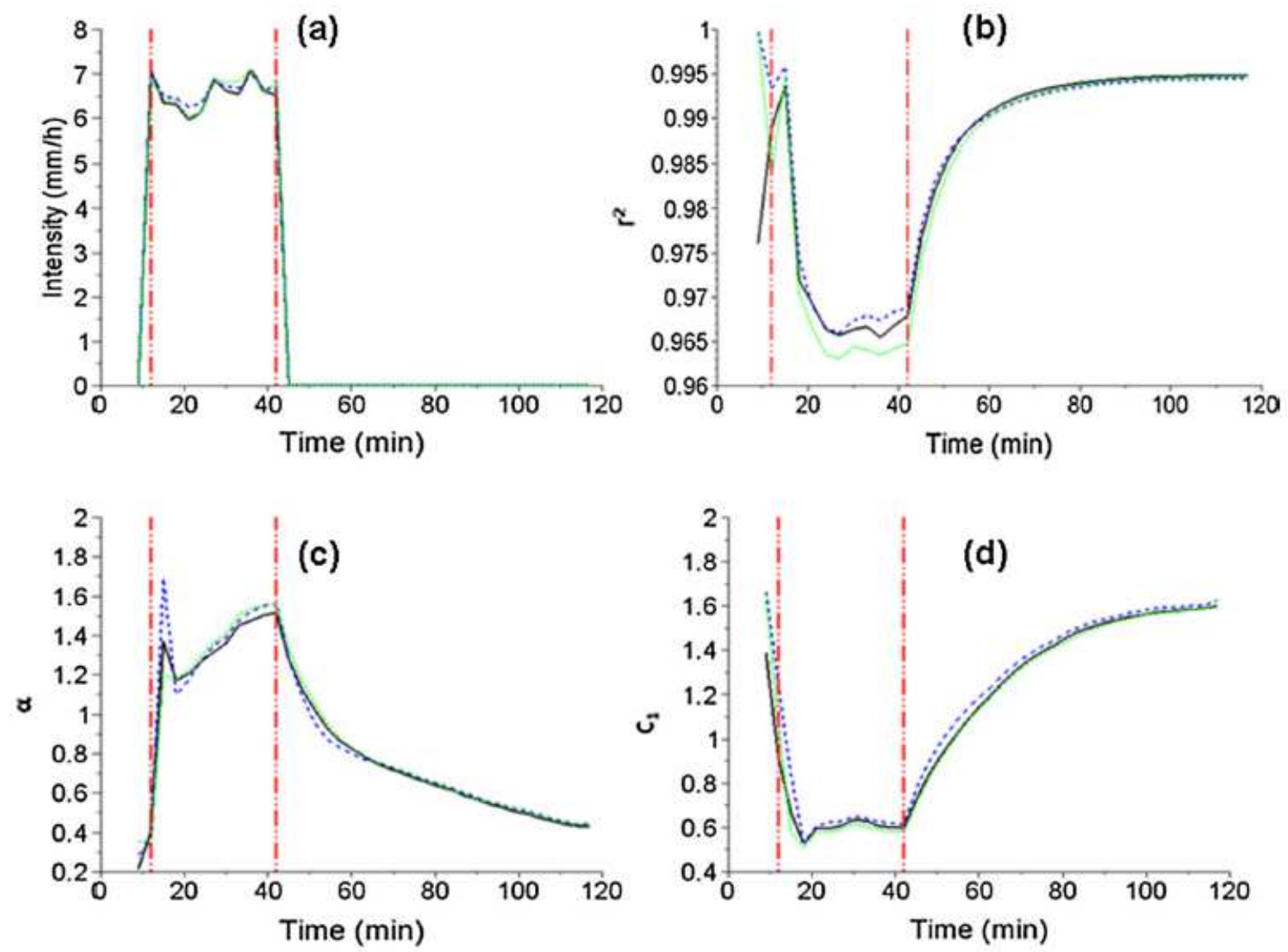

845

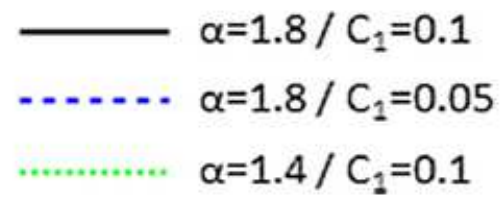

846 Figure 13: For three synthetic rainfall events with different sets of UM parameters; temporal

847 evolution of the average rain rate over the catchment (a), and for the simulated overland

848 maximum water depth, $r^{2}(\mathrm{~b}), \alpha(\mathrm{c})$ and $C_{1}(\mathrm{~d})$ for small scales $(10 \mathrm{~m}-80 \mathrm{~m})$.

849 